\title{
OFDM Uplink for Interactive Broadband Wireless: Analysis and Simulation in the Presence of Carrier, Clock and Timing Errors
}

\author{
Mohamed S. El-Tanany, Yiyan Wu, Fellow, IEEE, and László Házy
}

\begin{abstract}
This paper is concerned with the performance of OFDM when used as a modulation and access technique for the uplink of an interactive broadband wireless system or in the return link of a terrestrial television system. In such an application, the uplink performance becomes strongly dependent on the discrepancies related to carrier frequencies, sampling frequencies and time references used by different users. In addition, different uplink subcarriers will see different channels since individual subcarriers are allocated to different users. The main purpose of this paper is to provide the analytical tools necessary to quantify the performance of such an uplink by taking into consideration the error sources indicated above. The analysis is made from the uplink users' perspective; i.e., the results are presented with the subcarrier index as a parameter. Average uplink user performance is obtained by averaging over the tone index. Extensive computer simulations have been carried out and the results are in strong agreement with the analytical predictions.
\end{abstract}

Index Terms-Broadband wireless systems, interactive broadband, modulation, OFDM, uplink synchronization.

\section{INTRODUCTION}

B ROADBAND wireless access to the Internet has been the focus of research and development efforts of many research groups and organizations for the past few years, e.g., [2]-[6]. For example, reference [2] proposes a high speed asymmetrical wireless system based on EDGE uplink and OFDM downlink with the requirements envisioned for $3 \mathrm{G}$ systems in mind. Reference [3] focuses on the physical and MAC layer of the $2.4 \mathrm{GHz}$ and $5.2 \mathrm{GHz}$ band IEEE 802.11 standard as well as on the Magic WAND project as a precursor of the HiperLAN-2 standard. A description of the structure of the data packet, of the underlying OFDM symbol, and of the training and pilot signals is given for the OFDM based $5.2 \mathrm{GHz}$ band 802.11 standard and the Magic WAND project. OFDM has been adopted, or is being proposed, as the preferred transmission technique for several recent standards for wireless LANs and for fixed wireless access systems, especially in the unlicensed bands.

OFDM provides an effective method to mitigate the ISI occurring when wideband signaling over multipath radio channels is used. The main idea is to send the data in parallel over a number of narrowband flat fading subchannels (see Fig. 1). This

Manuscript received Febraury 8, 2001; revised March 14, 2001.

M. S. El-Tanany and L. Házy are with the Department of Systems and Computer Engineering, Carleton University, Ottawa, Ontario, K1S 5B6.

$\mathrm{Y}$. Wu is with the Communications Research Centre, Shirley Bay, Ottawa, Ontario.

Publisher Item Identifier S 0018-9316(01)04268-8.

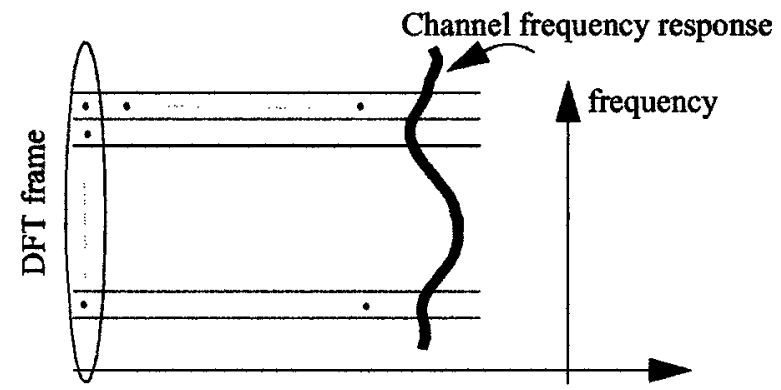

Fig. 1. Using OFDM to mitigate ISI.

is efficiently achieved by using a set of overlapping orthogonal signals to partition the channel. The transceiver can be realized using a number of coherent QAM modems which are equally spaced in the frequency domain, and which can be implemented by using the IDFT at the transmitter and the DFT at the receiver. However, due to the fact that the intercarrier spacing in OFDM is relatively small, OFDM transceivers are somewhat more sensitive to phase noise, frequency errors and sampling clock frequency errors by comparison to single carrier transceivers.

The performance achievable with uncoded OFDM over frequency selective fading channels is quite similar to the performance of single carrier QAM over flat fading channels. OFDM can only exploit the frequency diversity through the use of error correction coding. When combined with coding, OFDM is known as COFDM. Coded OFDM has been adopted in a number of applications including Digital Audio Broadcasting, Digital Video Broadcasting and wireless LAN. It is currently a strong contender before the 802.16 standards committee for wireless access systems below $11 \mathrm{GHz}$.

For an interactive broadband wireless system, OFDM clearly offers the advantage of ISI avoidance over frequency selective channels when used on the downlink. Its performance on the uplink remains unclear. It is the purpose of this paper to give a quantitative answer to this question.

The system block diagram of an OFDM uplink is presented in Fig. 2, where each uplink user $i$ is allocated one or more subcarriers. The subcarrier frequencies from all users form a set of $N$ orthogonal carriers by appropriate choice of the spacing, as it is done in OFDM. For the purpose of this paper, it is more convenient to view the OFDM signal as composed of the addition of a number of orthogonal data carrying subcarriers, as opposed to the common view of a data frame (OFDM symbol) composed of prefix and data symbols. The two representations are equivalent and the reader is referred to [1]. 


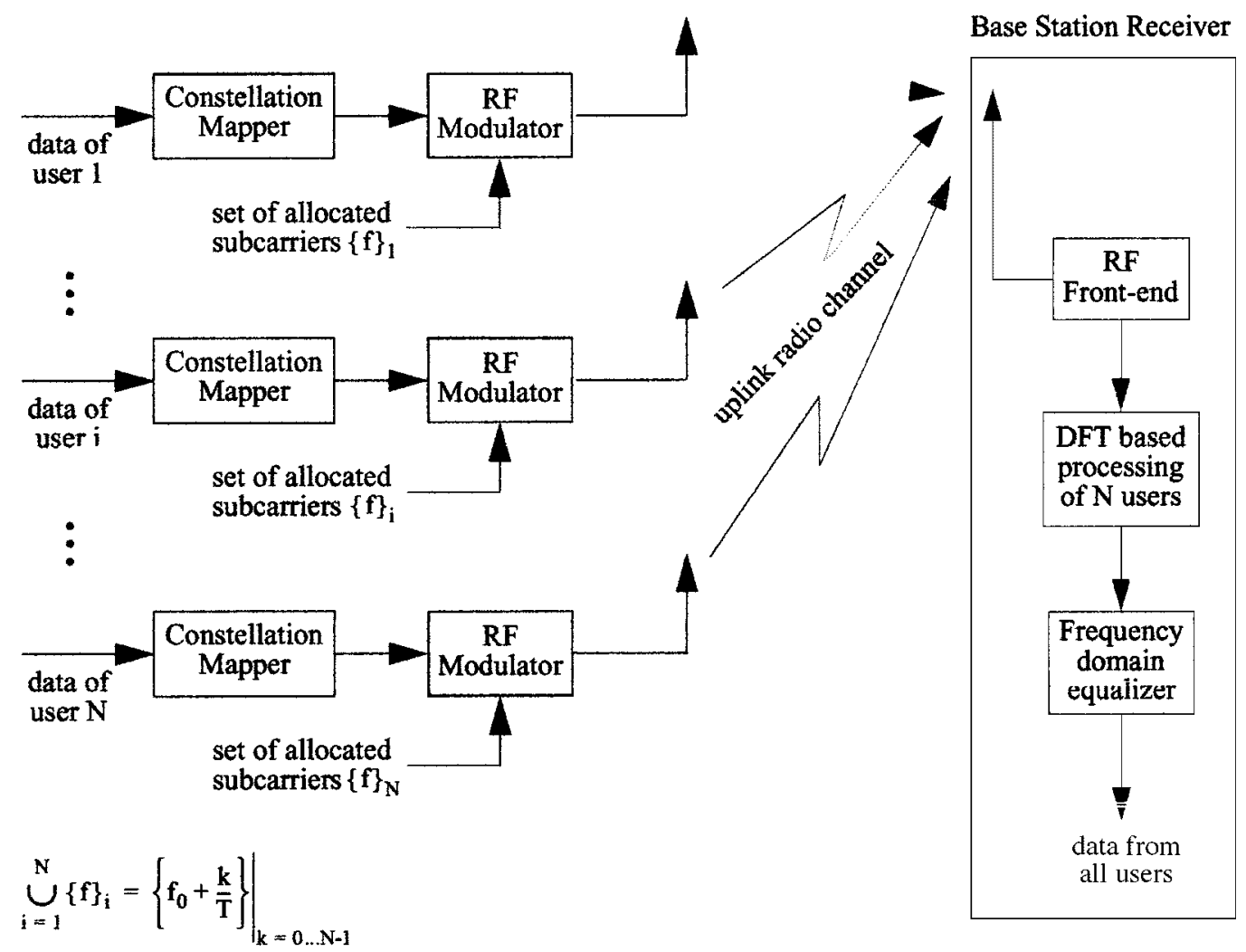

Fig. 2. OFDM uplink system diagram.

In order to gain some appreciation of the problem at hand, let us first enlist the benefits of using OFDM as an uplink transmission technique, along with the conditions under which these benefits hold:

- ISI avoidance on the uplink; this becomes more apparent as the transmission bandwidth increases.

- Provides a high level of flexibility in terms of frequency resource allocation; for example, a user may be assigned a certain tone for a certain period of time or, depending on his traffic requirements, several tones at once.

- From an end user equipment perspective, it is preferable to give individual users as few tones as possible at any given time. The motivation here is to try keeping the peak-toaverage power ratio as low as possible while increasing the transmission range (distance).

- In the event an individual user is given several tones to transmit on, such tones must be spaced sufficiently far apart in order to exploit the frequency diversity of the channel.

As such, we shall pursue our investigation with the assumption that each tone in an OFDM symbol is used by a different uplink user. As a result, as seen by the base station, each tone will experience a different channel, carrier frequency error, sampling frequency error and a different delay. Our investigation considers uncoded OFDM with the understanding that a raw error rate of $10^{-2}$ to $10^{-3}$ represents an acceptable performance threshold since FEC is likely to drop that by several orders of magnitude.

\section{EFFECT OF UPLINK CARRIER FREQUENCY ERRORS}

In this section we are concerned with the analysis of the uplink subject to carrier frequency errors only and we make the following assumptions:

- The remote terminals are perfectly synchronized in terms of OFDM symbol timing.

- The remote terminals are synchronized in terms of sampling clock frequency.

- As a worst case scenario, we assume that each uplink user transmits on only one tone.

- No guard tones are assumed to exist between traffic channels.

- The uplink channel response for each user varies independently of all other channels.

\section{A. Analysis}

With the above assumptions in mind, the signal received by the base station can be expressed in the form:

$$
\mathrm{s}(\mathrm{t})=\sum_{\mathrm{l}=0}^{\mathrm{N}-1} \mathrm{a}_{\mathrm{l}} \cdot \exp \left[\mathrm{j} 2 \pi \frac{\mathrm{lt}}{\mathrm{T}}\right] \cdot \exp \left[\mathrm{j} 2 \pi \mathrm{f}_{\mathrm{l}} \mathrm{t}\right] \cdot \mathrm{H}_{\mathrm{l}}
$$

where

$a_{l} \quad$ is a complex QAM symbol transmitted by the $l$ th user, and

$f_{l} \quad$ is the carrier frequency as generated by the $l$ th user equipment. 
$H_{l} \quad$ is the frequency response of the channel as seen by the $l$ th user and it is assumed to be a complex constant over one OFDM symbol period.

$f_{l}$ can be written in the form:

$$
\mathrm{f}_{\mathrm{l}}=\mathrm{f}_{0}+\delta_{\mathrm{cf}_{1}}
$$

where $f_{0}$ is the carrier frequency generated by the base station equipment and $\delta_{\mathrm{cf}_{l}}$ is the carrier frequency error of the equipment of the $l$ th user.

By substituting (2) in (1), the received signal at the base station can now be modeled as

$\mathrm{s}(\mathrm{t})=\exp \left[\mathrm{j} 2 \pi \mathrm{f}_{0} \mathrm{t}\right] \times \sum_{\mathrm{l}=0}^{\mathrm{N}-1} \mathrm{a}_{\mathrm{l}} \cdot \exp \left[\mathrm{j} 2 \pi \frac{\mathrm{lt}}{\mathrm{T}}\right] \cdot \exp \left[\mathrm{j} 2 \pi \delta_{\mathrm{cf}_{1}} \mathrm{t}\right] \cdot \mathrm{H}_{\mathrm{l}} \cdot$

The received signal is typically down-converted to baseband, sampled, and then applied to an FFT demodulator as a first step in the data detection process. When the number of carriers is relatively large, the function of the FFT block is nearly equivalent to a bank of $N$ correlators. The output of the $n$th correlator is equivalent to the $n$th FFT coefficient.

The output of the $n$th correlator is of the form:

$$
\begin{gathered}
\mathrm{x}_{\mathbf{n}}=\frac{1}{\mathrm{~T}} \cdot \int_{0}^{\mathrm{T}}\left(\exp \left[-\mathrm{j} 2 \pi \frac{\mathrm{nt}}{\mathrm{T}}\right] \times \sum_{\mathrm{l}=0}^{\mathrm{N}-1} \mathrm{a}_{\mathbf{l}} \cdot \exp \left[\mathrm{j} 2 \pi \frac{\mathrm{lt}}{\mathrm{T}}\right]\right. \\
\left.\cdot \exp \left[\mathrm{j} 2 \pi \delta_{\mathrm{cf}_{\mathrm{l}} \mathrm{t}} \mathrm{t}\right] \cdot \mathrm{H}_{\mathrm{l}}\right) \mathrm{dt}
\end{gathered}
$$

which can be rearranged as

$$
\begin{aligned}
\mathrm{x}_{\mathbf{n}}= & \sum_{\mathrm{l}=0}^{\mathrm{N}-1} \frac{\mathrm{a}_{\mathbf{l}} \mathrm{H}_{\mathbf{l}}}{\mathrm{T}} \times \int_{0}^{\mathrm{T}} \\
& \cdot\left(\exp \left[\mathrm{j} 2 \pi \frac{(1-\mathrm{n}) \mathrm{t}}{\mathrm{T}}\right] \cdot \exp \left[\mathrm{j} 2 \pi \delta_{\mathrm{cf}_{1}} \mathrm{t}\right]\right) \mathrm{dt} \\
\mathrm{x}_{\mathbf{n}}= & \sum_{\mathrm{l}=0}^{\mathrm{N}-1} \frac{\mathrm{a}_{\mathbf{l}} \mathrm{H}_{\mathrm{l}}}{\mathrm{T}} \times\left.\frac{\exp \left[\left(\mathrm{j} 2 \pi \frac{1-\mathrm{n}}{\mathrm{T}}+\mathrm{j} 2 \pi \delta_{\mathrm{cf}_{1}}\right) \mathrm{t}\right]}{\left(\mathrm{j} 2 \pi \frac{1-\mathrm{n}}{\mathrm{T}}+\mathrm{j} 2 \pi \delta_{\mathrm{cf}_{1}}\right)}\right|_{\mathrm{t}=0} ^{\mathrm{T}} \\
= & \sum_{\mathrm{l}=0}^{\mathrm{N}-1} \frac{\mathrm{a}_{\mathbf{l}} \mathrm{H}_{\mathbf{l}}}{\mathrm{T}} \times \exp \left[\left(\mathrm{j} \pi \frac{1-\mathrm{n}}{\mathrm{T}}+\mathrm{j} \pi \delta_{\mathrm{cf}_{1}}\right) \mathrm{T}\right] \\
& \times \frac{\sin \left(\pi \frac{1-\mathrm{n}}{\mathrm{T}}+\pi \delta_{\mathrm{cf}_{1}}\right) \mathrm{T}}{\left(\pi \frac{1-\mathrm{n}}{\mathrm{T}}+\pi \delta_{\mathrm{cf}_{1}}\right)} .
\end{aligned}
$$

In the equation above $x_{n}$ can be split into two components. A desired part, corresponding to the symbol transmitted by the $n$th user, and an interfering part. The desired component is given by

$$
\left.\mathrm{x}_{\mathbf{n}}\right|_{\text {desired }}=\mathrm{a}_{\mathbf{n}} \mathrm{H}_{\mathbf{n}} \times \exp \left[\mathrm{j} \pi \delta_{\mathrm{cf}_{1}} \mathrm{~T}\right] \times \frac{\sin \left(\pi \delta_{\mathrm{cf}_{1}} \mathrm{~T}\right)}{\left(\pi \delta_{\mathrm{cf}_{1}} \mathrm{~T}\right)}
$$

and the interfering component is given by

$$
\begin{aligned}
& =\sum_{\mathbf{l} \neq \mathbf{n}} \mathrm{a}_{\mathbf{l}} \mathrm{H}_{\mathbf{l}} \times \exp \left[\left(\mathrm{j} \pi \frac{1-\mathrm{n}}{\mathrm{T}}+\mathrm{j} \pi \delta_{\mathrm{cf}_{1}}\right) \mathrm{T}\right] \\
& \quad \times \frac{\sin \left(\pi \frac{1-\mathrm{n}}{\mathrm{T}}+\pi \delta_{\mathrm{cf}_{1}}\right) \mathrm{T}}{\left(\pi \frac{1-\mathrm{n}}{\mathrm{T}}+\pi \delta_{\mathrm{cf}_{1}}\right) \mathrm{T}} .
\end{aligned}
$$

Let us now assume that the carrier frequency errors are small compared to the OFDM symbol rate. In other words, $\delta_{\text {cf }_{l}} T \ll$ 1 for $0 \leq 1 \leq N-1$. Apart from this constraint, all frequency errors are assumed to be independent, identically distributed random variables. With this approximation, the interference term can be rewritten as follows:

$$
\begin{aligned}
& \left.\mathrm{x}_{\mathbf{n}}\right|_{\text {interference }} \\
& =\sum_{\mathrm{l} \neq \mathrm{n}}(-1)^{\mathbf{l}-\mathrm{n}} \times \mathrm{a}_{\mathbf{l}} \mathrm{H}_{\mathbf{l}} \times \exp \left[\mathrm{j} \pi(\mathrm{l}-\mathrm{n})+\mathrm{j} \pi \delta_{\mathrm{cf}_{1}} \mathrm{~T}\right] \\
& \quad \times \frac{\pi \delta_{\mathrm{cf}_{1}} \mathrm{~T}}{\left(\pi \frac{1-\mathrm{n}}{\mathrm{T}}+\pi \delta_{\mathrm{cf}_{1}}\right) \mathrm{T}} .
\end{aligned}
$$

Equation (9) represents a summation of a relatively large number of complex random variables which are identically distributed and statistically uncorrelated. This is because the set of channel gain coefficients and the set of data symbols, as well as the set of carrier frequency errors come from separate users. As a result, it is reasonable to assume that the interference term can be modeled as a complex Gaussian random variable with variance

$$
\begin{aligned}
\left.\sigma^{2}\right|_{\text {interference }} & =\sum_{l \neq n}\left|\mathrm{a}_{1}\right|^{2}\left|\mathrm{H}_{1}\right|^{2} \times\left[\frac{\delta_{\mathrm{cf}_{1}} \mathrm{~T}}{\left((1-\mathrm{n})+\delta_{\mathrm{cf}_{1}} \mathrm{~T}\right)}\right]^{2} \\
& \approx \sum_{\mathrm{l} \neq \mathrm{n}}\left|\mathrm{a}_{1}\right|^{2}\left|\mathrm{H}_{1}\right|^{2} \times\left|\frac{\delta_{\mathrm{cf}_{1}} \mathrm{~T}}{1-\mathrm{n}}\right|^{2}
\end{aligned}
$$

Based on (7) and (10) we can now express the signal-to-interference ratio of user $n$ :

$$
\operatorname{SIR}_{n}^{-1}=\frac{\left.\sigma^{2}\right|_{\text {interference }}}{\left|a_{n}\right|^{2}\left|H_{n}\right|^{2}}=\frac{\sum_{1 \neq n}\left|a_{1}\right|^{2} \cdot\left|H_{1}\right|^{2} \cdot\left|\frac{\delta_{\mathrm{cf}_{1}} \mathrm{~T}}{1-\mathrm{n}}\right|^{2}}{\left|\mathrm{a}_{\mathbf{n}}\right|^{2} \cdot\left|\mathrm{H}_{\mathbf{n}}\right|^{2}} \text {. }
$$

The SIR as given by (11) has been evaluated with the carrier frequency error as a parameter for a 256 carrier system. The results are shown in Fig. 3 which suggests that the SIR is only slightly dependent on the tone index $n$ and on the number of carriers. The SIR decreases at the rate of $6 \mathrm{~dB}$ every time the frequency error is reduced by a factor of 2 . Uplink carrier errors with a standard deviation of $1 \%$ relative to the subcarrier spacing yield an SIR of around $35 \mathrm{~dB}$. By doubling the carrier errors, the SIR is reduced to about $29 \mathrm{~dB}$. These SIR results are relatively insensitive to the number of carriers for $N$ between 64 and 256. It will be demonstrated later on that these SIR values play the 


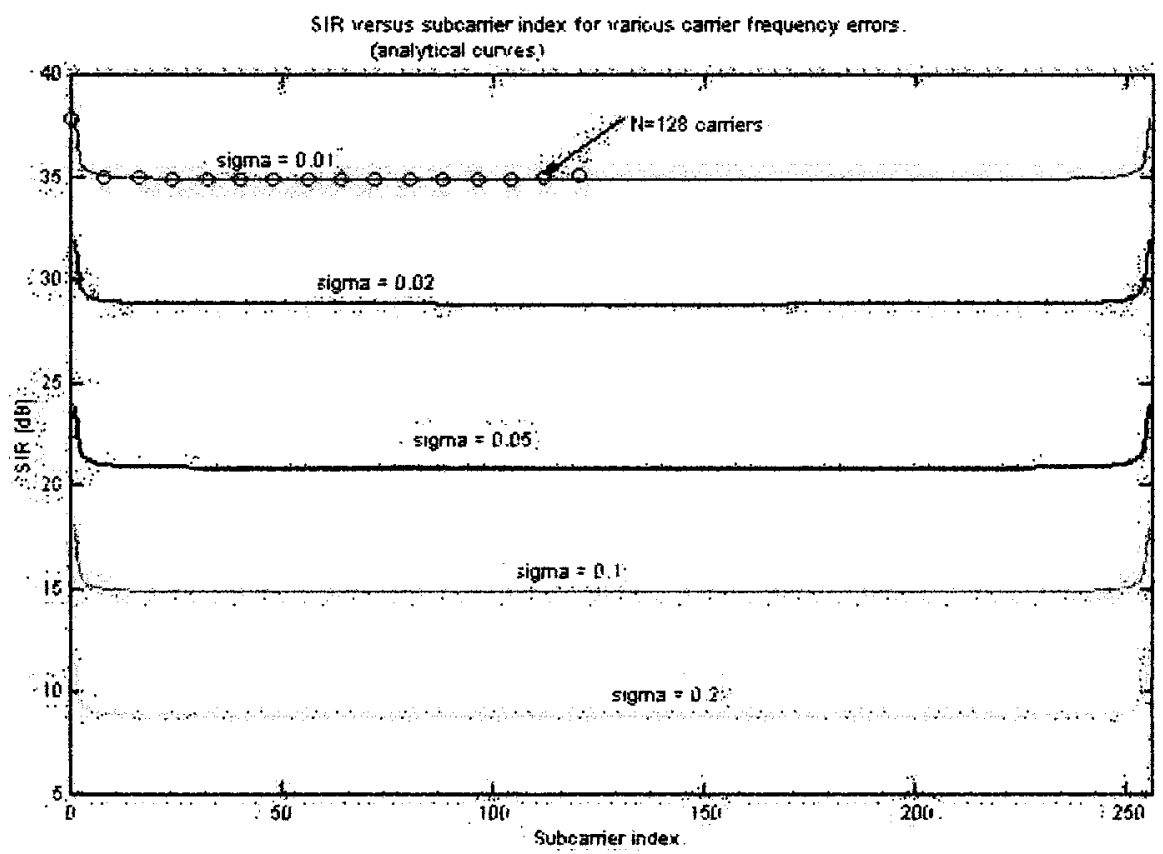

Fig. 3. Signal-to-interference ratio resulting from the uplink carrier frequency errors only, based on (11) for a system with 256 carriers. The results of a 128 carrier system are shown as circles.

important role of setting a lower bound on the SER performance of the uplink.

\section{EFFECT OF UPLINK SAMPLING ClOCK FREQUENCY ERRORS}

In this section we are concerned with the analysis of the uplink subject to sampling clock frequency errors only and we make the following assumptions:

- The remote terminals are perfectly synchronized in terms of OFDM symbol timing.

- The remote terminals are synchronized in terms of carrier frequency.

- As a worst case scenario, we assume that each uplink user transmits on only one tone.

- No guard tones are assumed to exist between traffic channels.

- The uplink channel response for each user varies independently of all other channels.

\section{A. Analysis}

With the above assumptions in mind, the signal received by the base station can be expressed in the form:

$$
\mathrm{s}(\mathrm{t})=\sum_{\mathrm{l}=0}^{\mathrm{N}-1} \mathrm{a}_{\mathrm{l}} \cdot \exp \left[\mathrm{j} 2 \pi \frac{\mathrm{lt}}{\mathrm{T}_{\mathrm{l}}}\right] \cdot \exp \left[\mathrm{j} 2 \pi \mathrm{f}_{0} \mathrm{t}\right] \cdot \mathrm{H}_{\mathrm{l}}
$$

where

$a_{l} \quad$ is a complex QAM symbol transmitted by the $l$ th user, and

$T_{l} \quad$ is the OFDM symbol period as generated by the $l$ th user equipment.

$H_{l} \quad$ is the frequency response of the channel as seen by the $l$ th user and it is assumed to be a complex constant over an OFDM symbol period.
$T_{l}$ can be written in the form:

$$
\mathrm{T}_{1}=\frac{\mathrm{N}}{\mathrm{f}_{\mathrm{s}_{1}}}=\frac{\mathrm{N}}{\mathrm{f}_{\mathrm{s}_{0}}+\delta_{\mathrm{sc}_{1}}}
$$

where

$f_{s_{l}} \quad$ is the sampling clock frequency of user $l$,

$f_{s_{0}} \quad$ is the sampling frequency of the base station and

$\delta_{s c_{l}}$ is the sampling clock error for user $l$.

By substituting (13) in (12), the received signal at the base station can now be modeled as

$$
\begin{aligned}
\mathrm{s}(\mathrm{t})= & \exp \left[\mathrm{j} 2 \pi \mathrm{f}_{0} \mathrm{t}\right] \times \sum_{\mathrm{l}=0}^{\mathrm{N}-1} \mathrm{a}_{\mathrm{l}} \cdot \mathrm{H}_{\mathrm{l}} \\
& \cdot \exp \left[\mathrm{j} \frac{2 \pi \mathrm{l}}{\mathrm{N}} \mathrm{f}_{\mathrm{s}_{0}} \mathrm{t}\right] \cdot \exp \left[\mathrm{j} \frac{2 \pi \mathrm{l}}{\mathrm{N}} \delta_{\mathrm{sc}_{1}} \mathrm{t}\right]
\end{aligned}
$$

The received signal is typically down-converted to baseband, sampled, and then applied to an FFT demodulator as a first step in the data detection process. When the number of carriers is relatively large, the function of the FFT block is nearly equivalent to a bank of $N$ correlators. The output of the $n$th correlator is equivalent to the $n$th FFT coefficient.

The output of the $n$th correlator is of the form:

$$
\begin{array}{r}
\mathrm{x}_{\mathrm{n}}=\frac{1}{\mathrm{~T}} \cdot \int_{0}^{\mathrm{T}}\left(\exp \left[-\mathrm{j} \frac{2 \pi \mathrm{n}}{\mathrm{N}} \mathrm{f}_{\mathrm{s}_{0}} \mathrm{t}\right] \times \sum_{\mathrm{l}=0}^{\mathrm{N}-1} \mathrm{a}_{\mathbf{l}} \cdot \mathrm{H}_{\mathrm{l}}\right. \\
\left.\cdot \exp \left[\mathrm{j} \frac{2 \pi \mathrm{l}}{\mathrm{N}} \mathrm{f}_{\mathrm{s}_{0}} \mathrm{t}\right] \cdot \exp \left[\mathrm{j} \frac{2 \pi \mathrm{l}}{\mathrm{N}} \delta_{\mathrm{sc}_{\mathrm{l}}} \mathrm{t}\right]\right) d t
\end{array}
$$


which can be rearranged as

$$
\begin{aligned}
& \mathrm{x}_{\mathbf{n}}=\sum_{\mathbf{l}=0}^{\mathrm{N}-1} \frac{\mathrm{a}_{\mathbf{l}} \mathrm{H}_{\mathbf{l}}}{\mathrm{T}} \\
& \times \int_{0}^{\mathrm{T}}\left(\exp \left[\mathrm{j} 2 \pi \frac{(1-\mathrm{n}) \mathrm{f}_{\mathrm{s}_{0}} \mathrm{t}}{\mathrm{N}}\right] \cdot \exp \left[\mathrm{j} \frac{2 \pi \mathrm{l}}{\mathrm{N}} \delta_{\mathrm{sc}_{1}} \mathrm{t}\right]\right) \mathrm{dt} \\
& \mathrm{x}_{\mathbf{n}}=\sum_{\mathrm{l}=0}^{\mathrm{N}-1} \frac{\mathrm{a}_{\mathbf{l}} \mathrm{H}_{\mathbf{l}}}{\mathrm{T}} \\
& \times\left.\frac{\exp \left[\left(j 2 \pi \frac{1-n}{N} f_{s_{0}}+j \frac{2 \pi l}{N} \delta_{\mathrm{sC}_{1}}\right) t\right]}{\left(j 2 \pi \frac{1-n}{N} f_{s_{0}}+j \frac{2 \pi l}{N} \delta_{\mathrm{sc}_{1}}\right)}\right|_{t=0} ^{\mathrm{T}} \\
& =\sum_{\mathrm{l}=0}^{\mathrm{N}-1} \frac{\mathrm{a}_{\mathrm{l}} \mathrm{H}_{\mathrm{l}}}{\mathrm{T}} \times \exp \left[\left(\mathrm{j} \pi \frac{1-\mathrm{n}}{\mathrm{N}} \mathrm{f}_{\mathrm{s}_{0}}+\mathrm{j} \frac{\pi \mathrm{l}}{\mathrm{N}} \delta_{\mathrm{sc}_{1}}\right) \mathrm{T}\right] \\
& \times \frac{\sin \left(\pi \frac{1-\mathrm{n}}{\mathrm{N}} \mathrm{f}_{\mathrm{s}_{0}}+\frac{\pi \mathrm{l}}{\mathrm{N}} \delta_{\mathrm{sc}_{1}}\right) \mathrm{T}}{\left(\pi \frac{1-\mathrm{n}}{\mathrm{N}} \mathrm{f}_{\mathrm{s}_{0}}+\frac{\pi \mathrm{l}}{\mathrm{N}} \delta_{\mathrm{sc}_{1}}\right)} .
\end{aligned}
$$

In the equation above, $x_{n}$ can now be split into two components. A desired part, corresponding to the symbol that has been transmitted by the $n$th user, and an interfering part. The desired component is given by

$$
\left.\mathrm{x}_{\mathbf{n}}\right|_{\text {desired }}=\mathrm{a}_{1} \mathrm{H}_{\mathrm{l}} \times \exp \left[\mathrm{j} \frac{\pi \mathrm{l}}{\mathrm{N}} \delta_{\mathrm{sc}_{1}} \mathrm{~T}\right] \times \frac{\sin \left(\frac{\pi \mathrm{l}}{\mathrm{N}} \delta_{\mathrm{sc}_{1}} \mathrm{~T}\right)}{\left(\frac{\pi \mathrm{l}}{\mathrm{N}} \delta_{\mathrm{sc}_{1}} \mathrm{~T}\right)}
$$

Recall that $f_{s_{0}}=N / T$ and then (18) can be rearranged as follows:

$$
\left.\mathrm{x}_{\mathbf{n}}\right|_{\text {desired }}=\mathrm{a}_{\mathbf{l}} \mathrm{H}_{\mathbf{l}} \times \exp \left[\mathrm{j} \pi \mathrm{l} \frac{\delta_{\mathrm{sC}_{1}}}{\mathrm{f}_{\mathrm{s}_{0}}}\right] \times \frac{\sin \left(\pi \mathrm{l} \frac{\delta_{\mathrm{sC}_{1}}}{\mathrm{f}_{\mathrm{s}_{0}}}\right)}{\left(\pi \mathrm{l} \frac{\delta_{\mathrm{sC}_{1}}}{\mathrm{f}_{\mathrm{s}_{0}}}\right)}
$$

The remaining terms make up an interference component of the form

$$
\begin{aligned}
& \left.\mathrm{x}_{\mathbf{n}}\right|_{\text {interference }} \\
& =\sum_{\mathrm{l}=0}^{\mathrm{N}-1}(-1)^{1-\mathrm{n}} \times \mathrm{a}_{\mathbf{l}} \mathrm{H}_{\mathrm{l}} \times \exp \left[\mathrm{j} \pi(1-\mathrm{n})+\mathrm{j} \pi \mathrm{l} \frac{\delta_{\mathrm{sc}_{\mathrm{l}}}}{\mathrm{F}_{\mathrm{s}_{0}}}\right] \\
& \quad \times \frac{\sin \left(\pi \mathrm{l} \frac{\delta_{\mathrm{sc}_{1}}}{\mathrm{f}_{\mathrm{s}_{0}}}\right)}{\pi(1-\mathrm{n})+\pi \mathrm{l} \frac{\delta_{\mathrm{sc}_{1}}}{\mathrm{f}_{\mathrm{s}_{0}}}} .
\end{aligned}
$$

We now make the assumption that $\delta_{s c_{l}} / f_{s_{0}} \ll 1$ so that $\sin \left(\left(\pi l \delta_{s c_{l}}\right) / f_{s_{0}}\right) \approx\left(\pi l \delta_{s c_{l}}\right) / f_{s_{0}}$ and (20) becomes

$$
\begin{aligned}
& \left.\mathrm{x}_{\mathbf{n}}\right|_{\text {interference }} \\
& =\sum_{\mathrm{l}=0}^{\mathrm{N}-1}(-1)^{1-\mathrm{n}} \times \mathrm{a}_{\mathbf{l}} \mathrm{H}_{\mathrm{l}} \times \exp \left[\mathrm{j} \pi(1-\mathrm{n})+\mathrm{j} \pi \mathrm{l} \frac{\delta_{\mathrm{sc}_{1}}}{\mathrm{f}_{\mathrm{s}_{0}}}\right] \\
& \quad \times \frac{1}{(1-\mathrm{n})} \times \frac{\delta_{\mathrm{sc}_{1}}}{\mathrm{f}_{\mathrm{s}_{0}}}
\end{aligned}
$$

Equation (21) represents a weighted summation of a relatively large number of complex random variables which are identically distributed and statistically uncorrelated. This is because the set of channel gain coefficients and the set of data symbols, as well as the set of carrier frequency errors come from separate users. Therefore, it is reasonable to assume that the interference term can be modeled as a complex, zero-mean Gaussian random variable with variance

$$
\left.\sigma^{2}\right|_{\text {interference }} \approx \sum_{\mathbf{l} \neq \mathbf{n}}\left|\mathrm{a}_{\mathbf{l}}\right|^{2}\left|\mathrm{H}_{\mathbf{l}}\right|^{2} \times\left|\frac{1}{(1-\mathrm{n})}\right|^{2} \times\left|\frac{\delta_{\mathrm{sc}_{1}}}{\mathrm{f}_{\mathrm{s}_{0}}}\right|^{2} .
$$

Based on (19) and (22) we can now express the signal-to-interference ratio of user $n$ as

$$
\begin{aligned}
\operatorname{SIR}_{\mathbf{n}}^{-1} & =\frac{\left.\sigma^{2}\right|_{\text {interference }}}{\left|\mathrm{a}_{\mathbf{n}}\right|^{2}\left|\mathrm{H}_{\mathbf{n}}\right|^{2}} \\
& =\frac{\sum_{\mathbf{l} \neq \mathbf{n}}\left|\mathrm{a}_{\mathbf{l}}\right|^{2}\left|\mathrm{H}_{\mathbf{l}}\right|^{2} \times\left|\frac{1}{(1-\mathrm{n})}\right|^{2} \times\left|\frac{\delta_{\mathrm{sc}_{\mathbf{l}}}}{\mathrm{f}_{\mathrm{s}_{0}}}\right|^{2}}{\left|\mathrm{a}_{\mathbf{n}}\right|^{2}\left|\mathrm{H}_{\mathbf{n}}\right|^{2}} .
\end{aligned}
$$

Equation (23) assumes that the receiver takes samples at a rate of $N$-samples per OFDM symbol. In many instances it may be preferable to down-convert the RF signal using an SSB demodulator, in which case we end up with a real signal that must be sampled at a rate of $2 N$ samples per OFDM symbol. In such cases the frequency error is doubled. This is the scenario we are pursuing in this paper. As such, (23) may now be rewritten as

$$
\begin{aligned}
\left.\mathrm{SIR}^{-1}\right|_{\mathbf{n}} & =\frac{\left.\sigma^{2}\right|_{\text {interference }}}{\left|\mathrm{a}_{\mathbf{n}}\right|^{2}\left|\mathrm{H}_{\mathbf{n}}\right|^{2}} \\
& =\frac{\sum_{\mathbf{l} \neq \mathbf{n}}\left|\mathrm{a}_{\mathbf{l}}\right|^{2}\left|\mathrm{H}_{\mathbf{l}}\right|^{2} \times\left|\frac{1}{(1-\mathrm{n})}\right|^{2} \times\left|2 \Delta \times 10^{-6}\right|^{2}}{\left|\mathrm{a}_{\mathbf{n}}\right|^{2}\left|\mathrm{H}_{\mathbf{n}}\right|^{2}}
\end{aligned}
$$

where $\Delta$ is the sampling clock frequency stability expressed in parts-per-million (ppm).

The SIR has been computed according to (24) with the stability of the sampling clock oscillator as a parameter. The results obtained for a 256-carrier OFDM system which uses 16-QAM modulation and for Gaussian distributed the clock errors are presented in Fig. 4. The results clearly indicate that:

- The subcarrier index plays an important role in determining the SIR value: subcarrier \#256 experiences an SNR that is about $30 \mathrm{~dB}$ lower than the value presented to subcarrier \#1. 


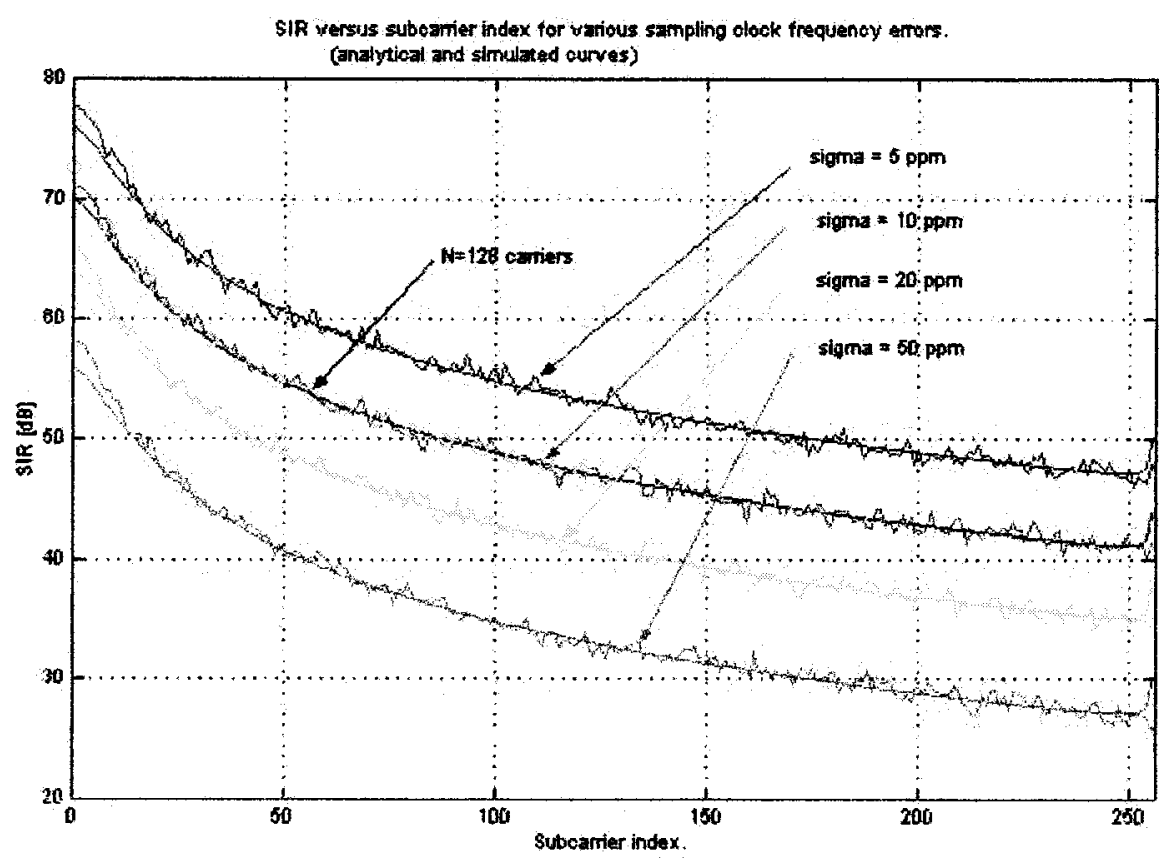

Fig. 4. SIR resulting from uplink sampling frequency errors in a 256 carrier system based on the analytical result of (24) (solid lines), and on simulation (dotted lines). Results for a 128 carrier system are shown as circles.

- The achievable SIR values for clock oscillator stabilities of $10 \mathrm{ppm}$ are quite high and even tolerable when 4-QAM or even 16-QAM are used for the modulation of individual subcarriers. Those same SIR values would become a problem for high-level constellations such as 64-QAM.

\section{EFFect OF Uplink Symbol Timing ERRORS}

In this section we are concerned with the analysis of the uplink subject to symbol timing errors only and we make the following assumptions:

- The remote terminals are synchronized in terms of sampling clock frequency.

- As a worst case scenario, we assume that each uplink user transmits on only one tone.

- No guard tones are assumed to exist between traffic channels.

- The uplink channel response for each user varies independently of all other channels.

- The uplink carrier frequencies are perfectly synchronized.

- The symbol timing errors are assumed to be small enough not to cause intersymbol interference (between different OFDM symbols); i.e., they are within the limits allowed by the cyclic prefix interval.

\section{A. Analysis}

With the above assumptions in mind, the signal received by the base station can be expressed in the form:

$$
\mathrm{s}(\mathrm{t})=\sum_{\mathrm{l}=0}^{\mathrm{N}-1} \mathrm{a}_{\mathbf{l}} \cdot \exp \left[\mathrm{j} 2 \pi \frac{1\left(\mathrm{t}-\tau_{1}\right)}{\mathrm{T}}\right] \cdot \exp \left[\mathrm{j} 2 \pi \mathrm{f}_{0} \mathrm{t}\right] \cdot \mathrm{H}_{1}
$$

where

$a_{l} \quad$ is a complex QAM symbol transmitted by the $l$ th user and $f_{0} \quad$ is the carrier frequency as generated by all uplink users' equipment.

$H_{l} \quad$ is the frequency response of the channel as seen by the lth user and is assumed to be a complex constant over an OFDM symbol period.

Equation (25) can be rewritten in the form:

$$
\begin{aligned}
\mathrm{s}(\mathrm{t})= & \exp \left[\mathrm{j} 2 \pi \mathrm{f}_{0} \mathrm{t}\right] \\
& \times \sum_{\mathrm{l}=0}^{\mathrm{N}-1} \mathrm{a}_{\mathbf{l}} \cdot \exp \left[\mathrm{j} 2 \pi \frac{\mathrm{lt}}{\mathrm{T}}\right] \cdot \exp \left[-\mathrm{j} 2 \pi \frac{\mathrm{l} \tau_{1}}{\mathrm{~T}}\right] \cdot \mathrm{H}_{\mathbf{l}} .
\end{aligned}
$$

The received signal is typically down-converted to baseband, sampled, and then applied to an FFT demodulator as a first step in the data detection process. When the number of carriers is relatively large, the function of the FFT block is nearly equivalent to a bank of $N$ correlators. The output of the $n$th correlator is equivalent to the $n$th FFT coefficient.

The output of the $n$th correlator is of the form:

$$
\begin{aligned}
\mathrm{x}_{\mathbf{n}}=\frac{1}{\mathrm{~T}} \cdot \int_{0}^{\mathrm{T}}\left(\exp \left[-\mathrm{j} 2 \pi \frac{\mathrm{nt}}{\mathrm{T}}\right] \times \sum_{\mathrm{l}=0}^{\mathrm{N}-1} \mathrm{a}_{\mathbf{l}}\right. \\
\left.\quad \exp \left[\mathrm{j} 2 \pi \frac{\mathrm{lt}}{\mathrm{T}}\right] \cdot \exp \left[-\mathrm{j} 2 \pi \frac{\mathrm{l} \tau_{1}}{\mathrm{~T}}\right] \cdot \mathrm{H}_{\mathrm{l}}\right) \mathrm{dt}
\end{aligned}
$$

which can be rearranged as

$$
\begin{aligned}
\mathrm{x}_{\mathbf{n}}= & \sum_{\mathrm{l}=0}^{\mathrm{N}-1} \frac{\mathrm{a}_{\mathbf{l}} \mathrm{H}_{\mathbf{l}}}{\mathrm{T}} \times \exp \left[-\mathrm{j} 2 \pi \frac{\mathrm{l} \tau_{\mathbf{l}}}{\mathrm{T}}\right] \\
& \times \int_{0}^{\mathrm{T}} \exp \left[\mathrm{j} 2 \pi \frac{(1-\mathrm{n}) \mathrm{t}}{\mathrm{T}}\right] \mathrm{dt} .
\end{aligned}
$$


The desired component of $x_{n}$ (corresponding to the data symbol of the $n$th user) is

$$
\left.\mathrm{x}_{\mathbf{n}}\right|_{\text {desired }}=\mathrm{a}_{\mathbf{n}} \mathrm{H}_{\mathbf{n}} \times \exp \left[-\mathrm{j} 2 \pi \frac{\mathrm{n} \tau_{\mathbf{n}}}{\mathrm{T}}\right]
$$

which is the $n$th QAM symbol modified by the frequency response of the channel and rotated by an angle which depends on the frequency index $n$ and on the relative delay of the $n$th user's signal. The interfering component of $x_{n}$ is of the form:

$$
\begin{aligned}
\left.\mathrm{x}_{\mathbf{n}}\right|_{\text {interferer }}= & \sum_{\mathbf{l} \neq \mathbf{n}} \frac{\mathrm{a}_{\mathbf{l}} \mathrm{H}_{\mathbf{l}}}{\mathrm{T}} \times \exp \left[-\mathrm{j} 2 \pi \frac{\mathrm{l} \tau_{1}}{\mathrm{~T}}\right] \\
& \times \int_{0}^{\mathrm{T}} \exp \left[\mathrm{j} 2 \pi \frac{(1-\mathrm{n}) \mathrm{t}}{\mathrm{T}}\right] \mathrm{dt}=0 .
\end{aligned}
$$

The timing errors do not produce an additive interference term as it was the case with carrier and sampling clock errors. It can be concluded that the timing error results in a rotation of the received QAM symbols. The set of rotations experienced by all 256 tones makes up a random variable. These rotations are additional to any rotation caused by the channel gain coefficients $\left\{H_{n}\right\}$. The aggregate rotation (due to uplink frequency errors, channel coefficients and relative uplink delays) is assumed to be taken care of by a frequency domain equalizer.

\section{Average SIR AND AVERAge SINR}

In this subsection we elaborate on the signal-to-interference ratio expressions presented earlier and we discuss how they will impact the uplink's signal-to-noise-plus-interference ratio. The main motivation for the discussion presented here is to derive an expression for the uplink degradation in terms of its SNR. For the sake of tractability, we will be dealing with averages over time and frequency.

First, consider a scenario where the carrier frequency errors are the only source of impairment. In this case, the variance of the interference is given by (10) which is repeated below for convenience:

$$
\left.\sigma^{2}\right|_{\text {interference }} \approx \sum_{\mathbf{l} \neq \mathbf{n}}\left|\mathrm{a}_{1}\right|^{2}\left|\mathrm{H}_{1}\right|^{2} \times\left|\frac{\delta_{\mathrm{cf}_{1}} \mathrm{~T}}{1-\mathrm{n}}\right|^{2} .
$$

The set $\left\{a_{l}\right\}$ of QAM symbols and $\left\{H_{l}\right\}$ of channel gains are $N$-dimensional complex random variables. The set of frequency errors $\left\{\delta_{\mathrm{cf}_{l}}\right\}$ is an $N$-dimensional real Gaussian variable. When averaged over the data symbols, channel gains and frequency errors, (31) yields:

$$
\begin{aligned}
\left\langle\left.\sigma^{2}\right|_{\text {int }}\right\rangle & =\sum_{\mathrm{l} \neq \mathrm{n}}\left\langle\left|\mathrm{a}_{\mathrm{l}}\right|^{2}\right\rangle\left\langle\left|\mathrm{H}_{\mathrm{l}}\right|^{2}\right\rangle \times\left\langle\left|\frac{\delta_{\mathrm{cf}_{1}} \mathrm{~T}}{1-\mathrm{n}}\right|^{2}\right\rangle \\
& =\left\langle\left|\mathrm{a}_{\mathbf{l}}\right|^{2}\right\rangle\left\langle\left|\mathrm{H}_{\mathbf{l}}\right|^{2}\right\rangle\left\langle\left|\delta_{\mathrm{cf}_{1}} \mathrm{~T}\right|^{2}\right\rangle \sum_{\mathrm{l} \neq \mathrm{n}}\left|\frac{1}{1-\mathrm{n}}\right|^{2} \\
& =\left|\overline{\left.a\right|^{2}}\right| \overline{\left.\mathrm{H}_{\mathrm{l}}\right|^{2}} \sigma_{\mathrm{cf}}^{2} \mathrm{~T}^{2} \sum_{\mathrm{l} \neq \mathrm{n}}\left|\frac{1}{1-\mathrm{n}}\right|^{2}
\end{aligned}
$$

and if we normalize the QAM symbol energy and the channel gains such that $|\overline{\mathrm{a}}|^{2}=1$ and $\mid \overline{\left.\mathrm{H}_{1}\right|^{2}}=1$ then the interference variance is reduced to:

$$
\left.\left\langle\left.\sigma^{2}\right|_{\text {int }}\right\rangle\right|_{\text {carrier frequency errors }}=\left(\sigma_{\mathrm{cf}}^{2} \mathrm{~T}^{2}\right) \sum_{\mathrm{l} \neq \mathbf{n}}\left|\frac{1}{1-\mathrm{n}}\right|^{2} .
$$

Let us now turn our attention to the sampling clock errors. The error variance is given by (22). When averaged over the QAM symbols, channel gains and the various users clock errors we end up with

$$
\left.\left\langle\left.\sigma^{2}\right|_{\text {int }}\right\rangle\right|_{\text {sampling clock errors }}=\left(\frac{\sigma_{\mathrm{sc}}^{2}}{\mathrm{f}_{\mathrm{s}_{0}}^{2}}\right) \sum_{\mathrm{l} \neq \mathbf{n}}\left|\frac{1}{1-\mathrm{n}}\right|^{2} .
$$

It will be assumed that the two types of errors above, and the additive thermal noise add on a power basis. Therefore, the compounded interference plus noise at the FFT output has a variance of the form:

$\sigma_{\text {total }}^{2}=\sigma_{\text {noise }}^{2}+\left(\sigma_{\mathrm{cf}}^{2} \mathrm{~T}^{2}\right) \sum_{\mathrm{l} \neq \mathbf{n}}\left|\frac{1}{1-\mathrm{n}}\right|^{2}+\left(\frac{\sigma_{\mathrm{sc}}^{2}}{\mathrm{f}_{\mathrm{s}_{0}}^{2}}\right) \sum_{\mathrm{l} \neq \mathbf{n}}\left|\frac{1}{1-\mathrm{n}}\right|^{2}$.

Equation (35) gives the total error variance for the $n$th user symbol at the output of the FFT block prior to frequency domain equalization. Following the frequency domain equalizer, the final error presented to the $n$th user's symbol for a given channel gain $\mathrm{H}_{\mathbf{n}}$ is given by

$$
\begin{gathered}
\left.\sigma_{\text {final }}^{2}\right|_{\text {for a givenH }} \\
=\frac{1}{\left|\mathrm{H}_{\mathrm{n}}\right|^{2}} \times\left[\sigma_{\text {noise }}^{2}+\left(\sigma_{\mathrm{cf}}^{2} T^{2}\right) \sum_{\mathrm{l} \neq \mathrm{n}}\left|\frac{1}{1-\mathrm{n}}\right|^{2}\right. \\
\left.\quad+\left(\frac{\sigma_{\mathrm{sc}}^{2}}{\mathrm{f}_{\mathrm{s}_{0}}^{2}}\right) \sum_{\mathrm{l} \neq \mathrm{n}}\left|\frac{1}{1-\mathrm{n}}\right|^{2}\right] .
\end{gathered}
$$

The average interference presented to $n$th user's signal is obtained by averaging (36) over the $n$th user's channel gain

$$
\begin{aligned}
\sigma_{\text {final }}^{2}=\left\langle\frac{1}{\left|\mathrm{H}_{\mathbf{n}}\right|^{2}}\right\rangle \times & {\left[\sigma_{\text {noise }}^{2}+\left(\sigma_{\mathrm{cf}}^{2} \mathrm{~T}^{2}\right) \sum_{\mathrm{l} \neq \mathrm{n}}\left|\frac{1}{1-\mathrm{n}}\right|^{2}\right.} \\
& \left.+\left(\frac{\sigma_{\mathrm{sc}}^{2}}{\mathrm{f}_{\mathrm{s}_{0}}^{2}}\right) \sum_{\mathrm{l} \neq \mathbf{n}}\left|\frac{1}{1-\mathrm{n}}\right|^{2}\right]
\end{aligned}
$$

which can be rearranged in the form:

$$
\begin{aligned}
\sigma_{\text {final }}^{2}= & \left\langle\frac{\sigma_{\text {noise }}^{2}}{\left|\mathrm{H}_{\mathbf{n}}\right|^{2}}\right\rangle \\
& \times\left[1+\frac{\left(\sigma_{\mathrm{cf}}^{2} \mathrm{~T}^{2}\right) \sum_{\mathrm{l} \neq \mathbf{n}}\left|\frac{1}{1-\mathrm{n}}\right|^{2}+\left(\frac{\sigma_{\mathrm{sc}}^{2}}{\mathrm{f}_{\mathrm{s}_{0}}^{2}}\right) \sum_{\mathrm{l} \neq \mathbf{n}}\left|\frac{1}{1-\mathrm{n}}\right|^{2}}{\sigma_{\text {noise }}^{2}}\right] .
\end{aligned}
$$




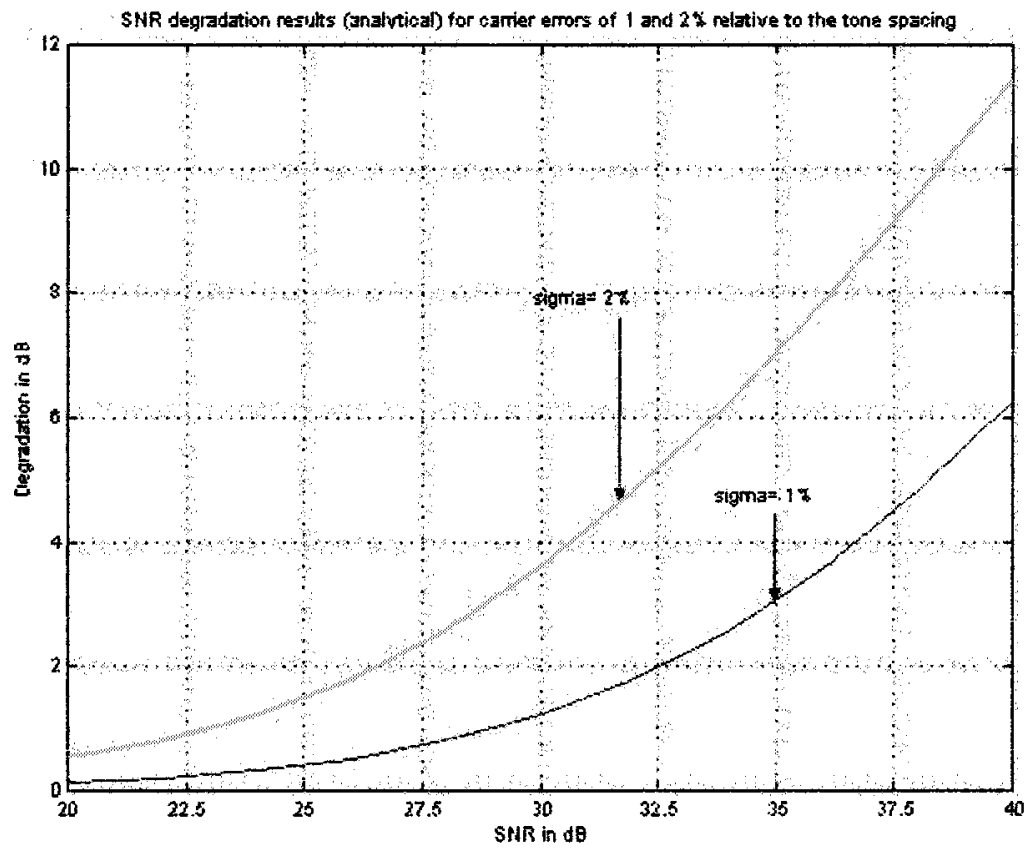

Fig. 5. Analytical results of the SNR degradation according to (39). The clock frequency stability is fixed at 10 parts per million.

Therefore, the SNR degradation resulting from both carrier and sampling frequency errors can be written as

\section{$\triangle \mathrm{SNR}$}

$$
\begin{aligned}
= & 10 \times \log _{10} \\
& \times\left(1+\frac{\left(\sigma_{\mathrm{cf}}^{2} \mathrm{~T}^{2}\right) \sum_{\mathrm{l} \neq \mathrm{n}}\left|\frac{1}{1-\mathrm{n}}\right|^{2}+\left(\frac{\sigma_{\mathrm{sc}}^{2}}{\mathrm{f}_{\mathrm{s}_{0}}^{2}}\right) \sum_{\mathrm{l} \neq \mathbf{n}}\left|\frac{1}{1-\mathrm{n}}\right|^{2}}{\sigma_{\text {noise }}^{2}}\right) .
\end{aligned}
$$

The average SNR degradation for the uplink has been evaluated according to (39) after averaging the bracketed expression over $n$ with the carrier frequency error as a parameter. The results are shown in Fig. 5 and they clearly suggest that the SNR degradation increases rapidly with nominal link signal-to-noise ratio and with the carrier frequency errors. From this perspective, the uplink should be operated at the lowest SNR that would yield an error rate above the system threshold (say 0.01). For example, a system operating at an SNR of $20 \mathrm{~dB}$ will experience degradations of no more than $0.5 \mathrm{~dB}$ for carrier errors of $1 \%$ or less. A system operating at $35 \mathrm{~dB}$ will experience degradation of about $3 \mathrm{~dB}$ when the carrier errors are $1 \%$ of the subcarrier spacing.

\section{System Simulation}

\section{A. System Model}

The model used for simulating the uplink performance is shown in Fig. 6. The main features of our model are the following:

- Each uplink user transmits only one QAM symbol per OFDM symbol. The QAM symbol is represented as a complex QAM constellation point and denoted by $a_{l}$ on the figure.

- The QAM symbol is applied to a single-side-band (SSB) ${ }^{1}$ modulator with a nominal carrier frequency $f_{0}$. The modulator output for a given user will be a single frequency sinusoid of duration equal to an OFDM symbol period plus a guard interval.

- The nominal frequency of the $l$ th SSB modulator is $f_{0}+$ $1 \cdot T_{\text {ofdm }}^{-1}+\delta_{c f}$ where $T_{\text {ofdm }}$ is the OFDM symbol period as seen by the $l$ th user and which is affected by the sampling clock errors. The term $\delta_{c f}$ is the carrier frequency error caused by the $l$ th user equipment (and possibly by the doppler shift).

- The carrier frequency errors of all users for a given OFDM symbol are generated using a random number generator with either uniform or Gaussian distribution.

- The sampling clock errors for all uplink users are also provided by a separate Gaussian or uniform random number generator.

- The sets of carrier frequency and sampling clock frequency errors applied to the uplink are changed from one OFDM symbol to the next.

- The SSB modulators' outputs are applied to separate channels. Each channel is represented by its complex frequency response (a single tap) and its delay. The channel responses are jointly complex Gaussian and are generated using a complex Gaussian random number generator.

- The front-end of the base station's receiver is modeled as a summing junction for all uplink users. Thermal noise is then added to the combined signal.

${ }^{1} \mathrm{SSB}$ modulators and demodulators have been used in this study as they are more tractable for analysis and simulation purposes. The results presented also apply to the case in which quadrature modulators/demodulators are used. The only difference is that the sampling clock errors will be reduced since the sampling clock frequency is reduced by a factor of 2 . 


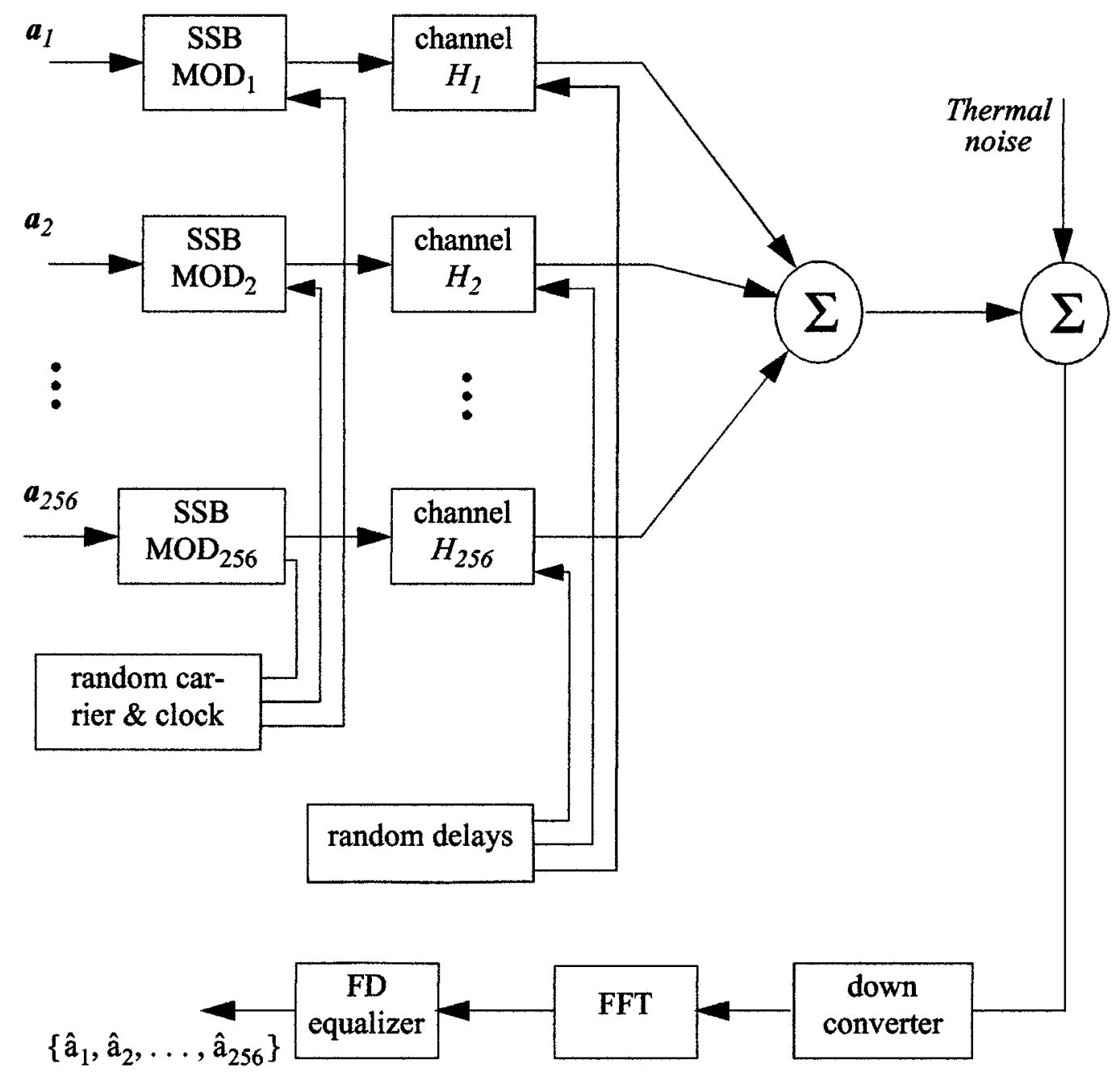

Fig. 6. Uplink simulation model. The SSB modulators are driven by random carrier frequency errors and random sampling frequency errors.

- The combined signal plus noise is applied to a down converter with a nominal carrier frequency $f_{0}$ and then it is applied to an FFT demodulator.

- The desired component of each FFT coefficient represents a QAM symbol scaled in magnitude by the channel. It is also rotated in phase due to the channel, random carrier and sampling frequency errors and also due to random delays. $^{2}$

- The FFT output is applied to a frequency domain equalizer which is assumed to have knowledge of the amplitude scaling and phase rotation of each user. Such information is usually derived from pilot symbols which, for example, can be transmitted by each user during certain established time slots.

This model has been implemented in Matlab in order to examine the system performance sensitivity to uplink random carrier and sampling clock frequency errors as well as timing errors.

\section{B. Discussions and Results}

Distribution of the Received QAM Symbols: Recall that as a result of the uplink errors, each of the received symbols consists

${ }^{2}$ The random delays are small compared to the prefix interval. of a desired component and an interferece term. The first objective of this simulation was to quantify the interfering part and gain insight into its distribution.

Fig. 7 shows an example histogram for the interfering term (real and imaginary) based on a simulation run of 128 OFDM symbols, each consisting of 256 16-QAM modulated carriers. The frequency error distribution is approximately Gaussian with a standard deviation of $3 \%$ of the carrier spacing. The general shape depicted is quite typical for other values of the frequency error and even when the carrier distribution was modeled as uniform. The distribution was not found to vary with the size of the signal constellation.

Fig. 8 shows the 16-QAM constellation at the FD equalizer output. This plot is based on the simulation of 128 OFDM symbols in the presence of uplink carrier errors with a standard deviation of $\sigma=3 \%$ of the carrier spacing. The additive noise is $80 \mathrm{~dB}$ below the signal. The dispersion seen has resulted from uplink carrier frequency errors only. The general appearance is similar to what would be expected as a result of additive Gaussian noise.

The sampling clock frequency errors were found to yield qualitatively similar results in terms of the distribution of the interfering term and its impact on the signal constellation. 


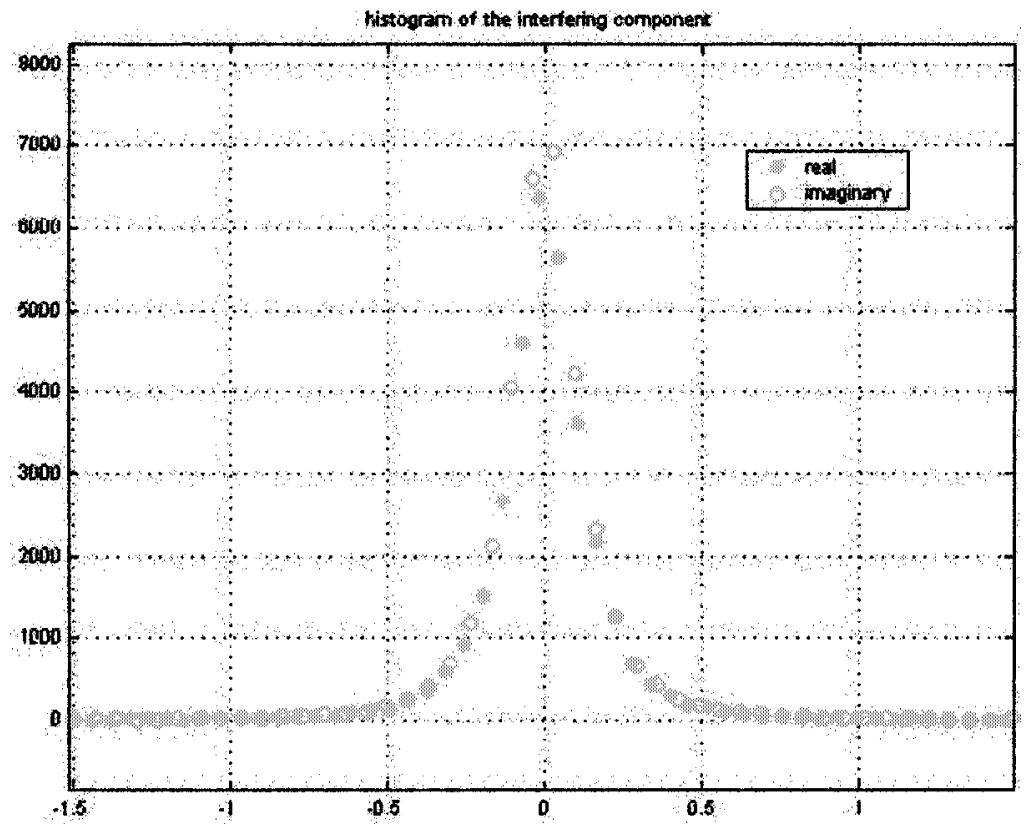

Fig. 7. An example histogram showing the distribution of the real and imaginary parts of the interference term caused by carrier frequency errors.

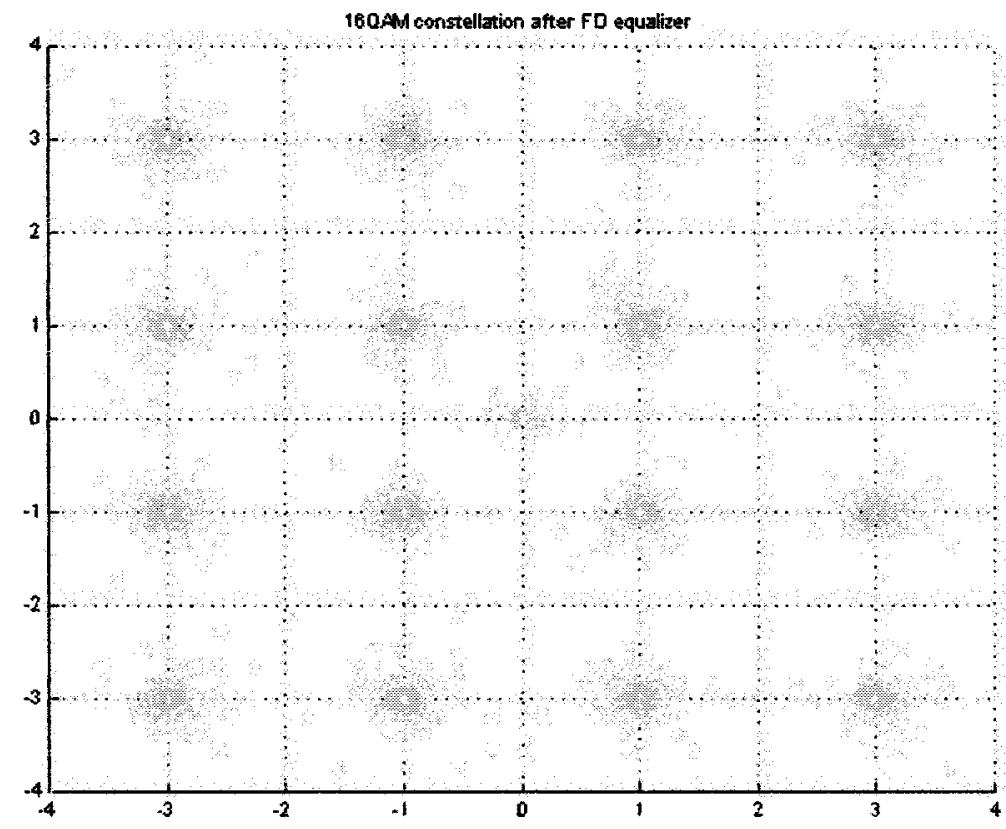

Fig. 8. 16QAM constellation at the output of the FD equalizer.

However, assuming clock stabilities of $10 \mathrm{ppm}$, the interference becomes noticeable only on higher level QAM constellations.

SIR and SINR: In the absence of noise, the performance of the receiver will depend on the ratio between the power of the desired signal and the power of the interfering component. The signal-to-interference ratio (SIR) has been given analytically by (11) and (24) for the cases of carrier errors and sampling frequency errors respectively. The simulation model also generates SIR results as by-products, thus providing a means for verifying the analysis.

Carrier Frequency Errors: Let us first consider the carrier frequency errors. By averaging (11) over the tone index $n$ we obtain an average SIR which has been plotted in Fig. 9 (analytical result) with the frequency error as a parameter. The simulation results are generated using a 16-QAM constellation and Gaussian distributed carrier frequency errors. Repeated simulation runs suggest that SIR is relatively insensitive to the signal constellation and to the distribution of the carrier errors.

In one of the cases we only use every second tone for information transmission while the remaining tones are used as a frequency guard between the uplink users. Based on these results we notice that:

- Using a guard tone increases the average SIR by $6 \mathrm{~dB}$.

- Strong agreement between the predictions of (11) and the simulation results. 


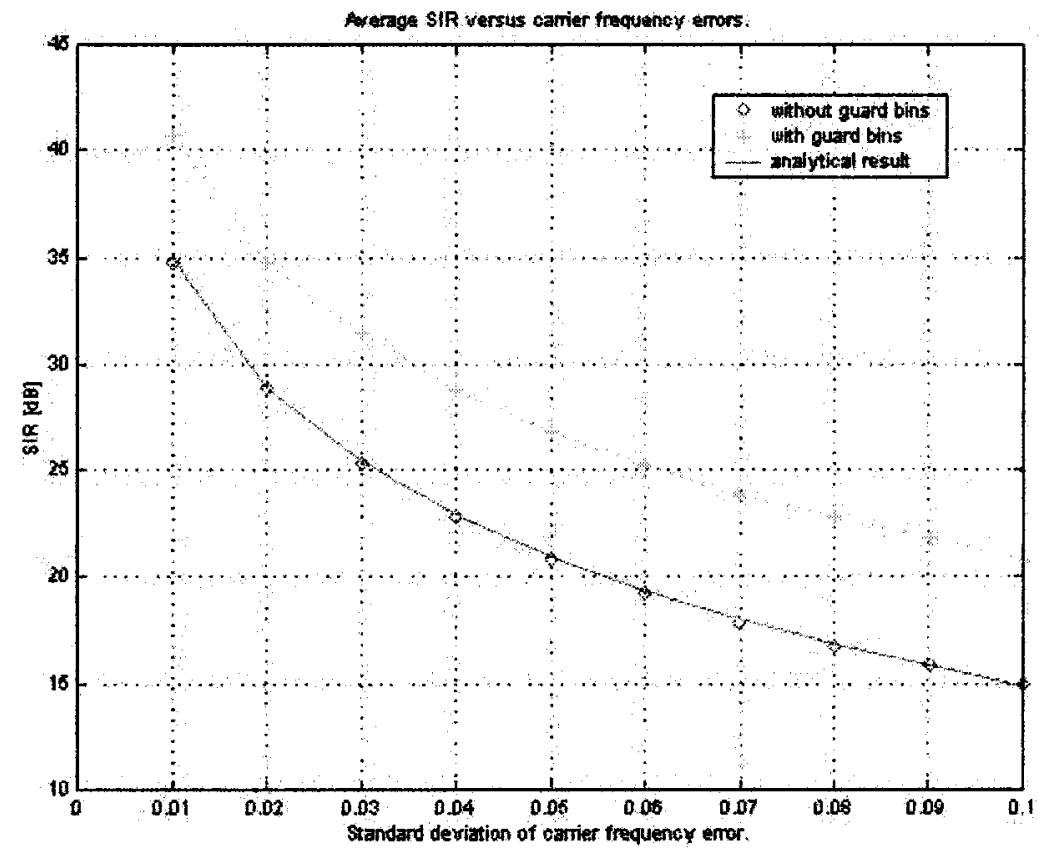

Fig. 9. Average signal-to-interference ratio due to carrier frequency errors.

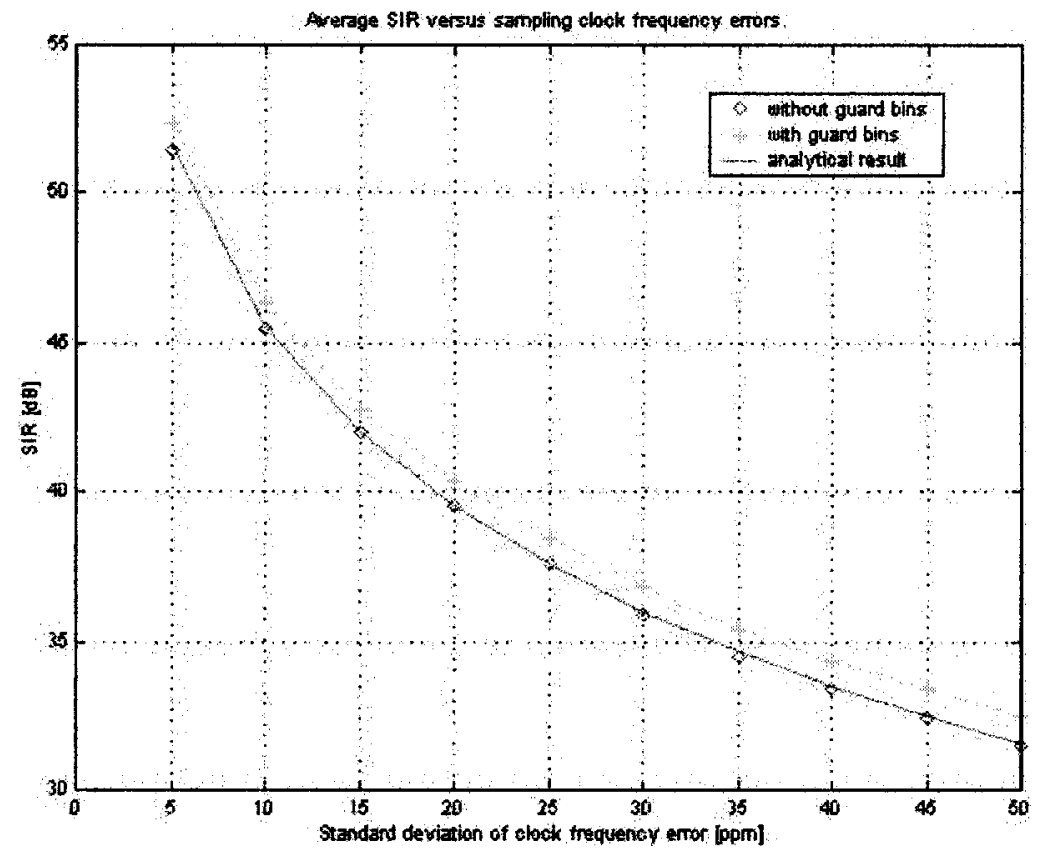

Fig. 10. Average SIR versus the frequency stability of the uplink clock oscillators based on analysis and on simulation.

The simulations also showed that the average SIR results are not affected by the size of the QAM constellation nor the distribution of the carrier frequency errors.

Sampling Clock Frequency Errors: The results obtained for the SIR due to errors in the sampling frequencies of individual uplink users are given by (24). Fig. 4 shows the analytical values of SIR versus the frequency index of the uplink user. These results show strong dependence on the frequency index: a user on tone \#256 faces about $30 \mathrm{~dB}$ reduction in SIR by comparison to a user on tone \#1. The same figure shows the results obtained by simulation based on 128 OFDM symbols modulated using 16-QAM constellations. The simulation results appeared insensitive to the size of the QAM constellation and to the statistical distribution of the sampling frequency errors.

These results indicate that clock stabilities around $10 \mathrm{ppm}$ would yield an SIR higher than $40 \mathrm{~dB}$, which is well above the average SNR of many wireless systems. As such, little performance degradation is to be expected from free running crystalcontrolled clock oscillators.

The averaged (over all frequency indices) SIR results are shown in Fig. 10 as a function of the frequency stability of the uplink clock oscillators. The analytical results are based on (24). 


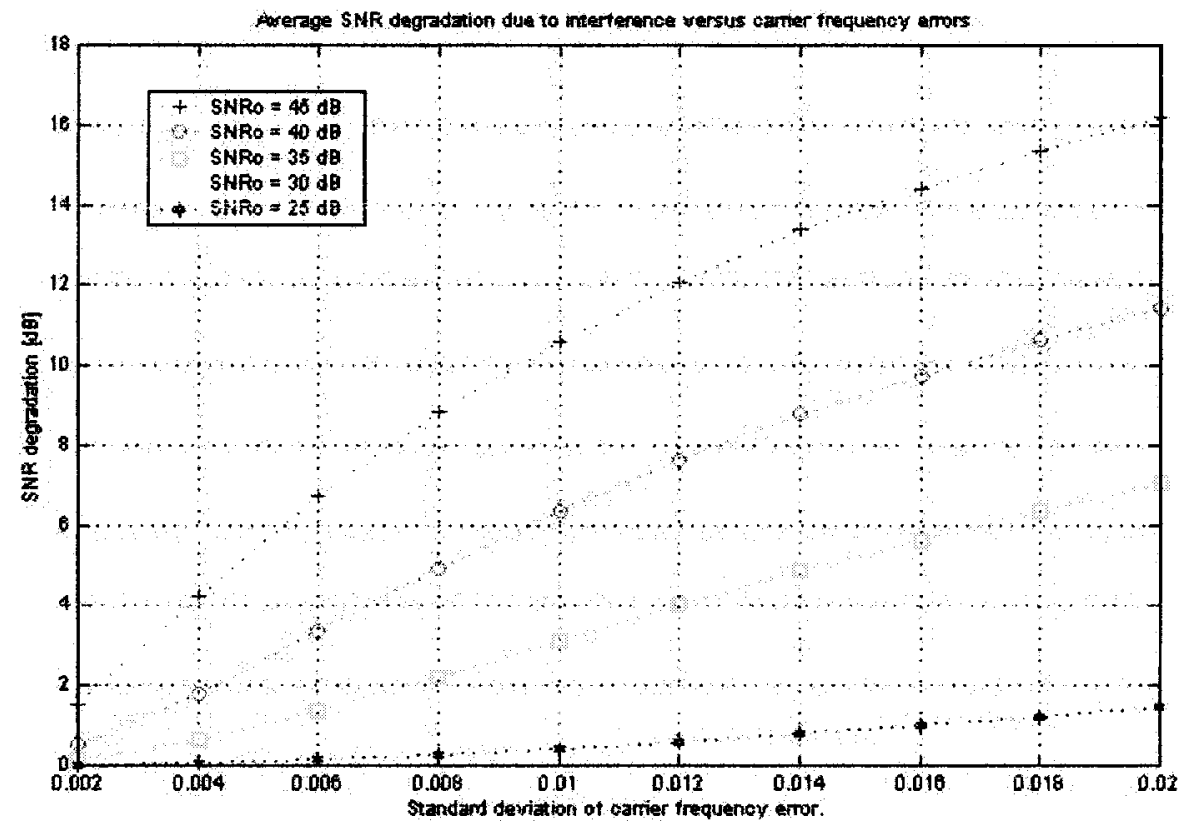

Fig. 11. Simulation results of the SNR degradation based on 128 OFDM symbols modulated using 16-QAM constellations.

SNR Degradation: The SNR degradation is defined as follows:

SNR degradation

or

$$
=\frac{\text { signal to noise ratio }}{\text { signal to noise plus interference ratio }}
$$

SNR degradation $(\mathrm{dB})$

$=$ signal to noise ratio $(\mathrm{dB})$

- signal to noise plus interference ratio $(\mathrm{dB})$

The analytical results for the SNR degradation are given by (39) as a function of the carrier frequency errors, clock errors and the SNR. These results are presented in Fig. 5 for carrier errors of $1 \%$ and $2 \%$ relative to the tone spacing. In both cases the clock stability is fixed at $10 \mathrm{ppm}$. As expected, these results suggest a rapid increase of the degradation with the SNR and with the carrier frequency errors.

Fig. 11 presents the SNR degradation results based on simulation as a function of the carrier frequency errors. A clock stability of $10 \mathrm{ppm}$ is assumed for all cases. These results were found insensitive to the statistical distribution of both clock and carrier errors.

The agreement between the analytical and simulation results is very good. For example, assuming an SNR of $40 \mathrm{~dB}$ and carrier errors of $1 \%$, the analytical result in Fig. 5 suggests a $6.2 \mathrm{~dB}$ while the simulation result in Fig. 11 suggests $6.4 \mathrm{~dB}$ of SNR degradation.

\section{Symbol ERROR RATE ANALYSIS AND SimUlation}

The Appendix gives a derivation of the probability of symbol errors for an OFDM system with $M$-ary QAM modulation operating over fading channels subject to the following conditions:

- The tone spacing is much smaller than the coherence bandwidth of the channel.
- The transmission bandwidth is large compared to the coherence bandwidth of the channel.

- The signal is disturbed by additive white Gaussian noise only.

By incorporating the SNR degradation caused by the uplink carrier and clock errors into the results of the Appendix, the average symbol error rate can be rewritten as:

$$
\begin{aligned}
\overline{\mathrm{P}_{\mathrm{e}}}= & \cdot\left(1-\frac{1}{\sqrt{\mathrm{M}}}\right) \cdot(1-\xi)-\left(1-\frac{1}{\sqrt{\mathrm{M}}}\right)^{2} \\
& \cdot\left[1-2 \cdot \xi+\frac{4}{\pi} \cdot \xi \cdot \operatorname{atan}(\xi)\right]
\end{aligned}
$$

where

and

$$
\xi=\sqrt{\frac{\mathrm{a}}{1+\mathrm{a}}}
$$

$$
\mathrm{a}=\frac{3 \bar{\gamma}}{2(\mathrm{M}-1)}
$$

with

$$
\bar{\gamma}=\frac{\frac{\mathrm{E}_{\mathrm{av}}}{\mathrm{N}_{0}}}{1+\frac{\mathrm{E}_{\mathrm{av}}}{\mathrm{N}_{\mathrm{o}}} \times\left[\left(\sigma_{\mathrm{cf}}^{2} \mathrm{~T}^{2}\right) \sum_{1 \neq \mathrm{n}}\left|\frac{1}{1-\mathrm{n}}\right|^{2}+\left(\frac{\sigma_{\mathrm{sc}}^{2}}{\mathrm{f}_{\mathrm{S}_{0}}^{2}}\right) \sum_{1 \neq \mathrm{n}}\left|\frac{1}{1-\mathrm{n}}\right|^{2}\right]} .
$$

The average symbol error rate results have been obtained for two cases, 4-QAM and 16-QAM, assuming a fading channel subject to the constraints indicated above. Fig. 12 shows the 4-QAM simulation results obtained for a nonfading channel for carrier errors with $\sigma=1 \%$ and $2 \%$ of the tone spacing, and for sampling clock stabilities of $10 \mathrm{ppm}$. Both the clock and carrier frequency errors were generated using normally distributed 


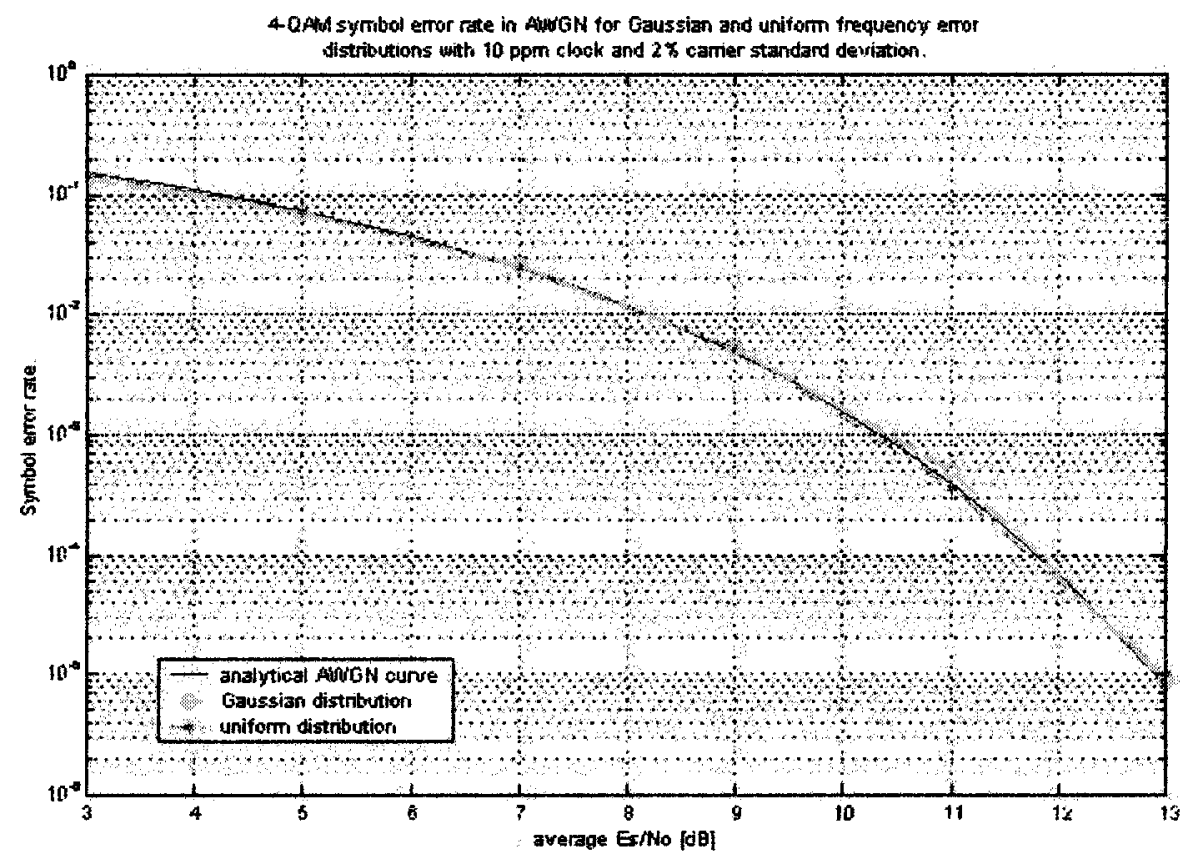

Fig. 12. Symbol error rate of 4-QAM over additive white Gaussian noise channels.

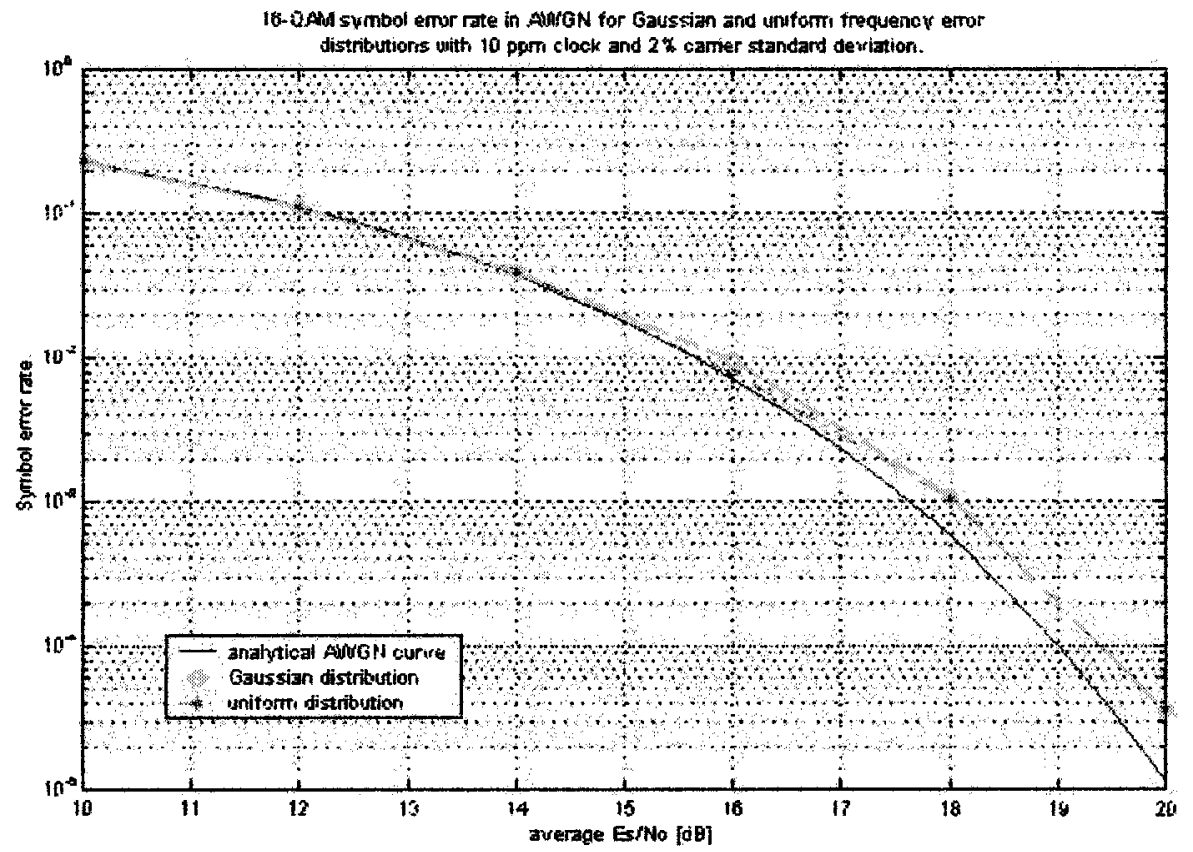

Fig. 13. Symbol error rate of 16-QAM over additive white Gaussian noise channels.

random number generators. The same figure shows the ideal (analytical) 4-QAM curve in the absence of any carrier or clock errors. Similar results for 16-QAM are shown in Fig. 13. From these results it can be concluded that the performance degradation is negligible when the carrier frequency errors are kept below $2 \%$.

The 4-QAM and 16-QAM simulation results for fading channels are shown in Figs. 14 and 15. In both cases we assumed uplink carrier frequency errors with $\sigma=0.5 \%, 1 \%$ and $2 \%$ of the tone spacing, and sampling clock stabilities of $10 \mathrm{ppm}$. Both the clock and carrier frequency errors were generated using normally distributed random number generators. The channel frequency response coefficients are generated using a normally distributed complex random number generator. The analytical SER curves are also shown for comparison purposes. From these two figures we notice that:

- The agreement between the analysis and simulation results seems good for all practical purposes.

- In the case of 4-QAM we notice that frequency errors of $2 \%$ or less cause negligible degradation at error rates of $10^{-2}$ or more. The degradation increases to about $4 \mathrm{~dB}$ for error rates of $2 \times 10^{-3}$.

- In the case of 16-QAM we find that frequency errors of $2 \%$ cause a $7 \mathrm{~dB}$ degradation at an error rate of $10^{-2}$. The 


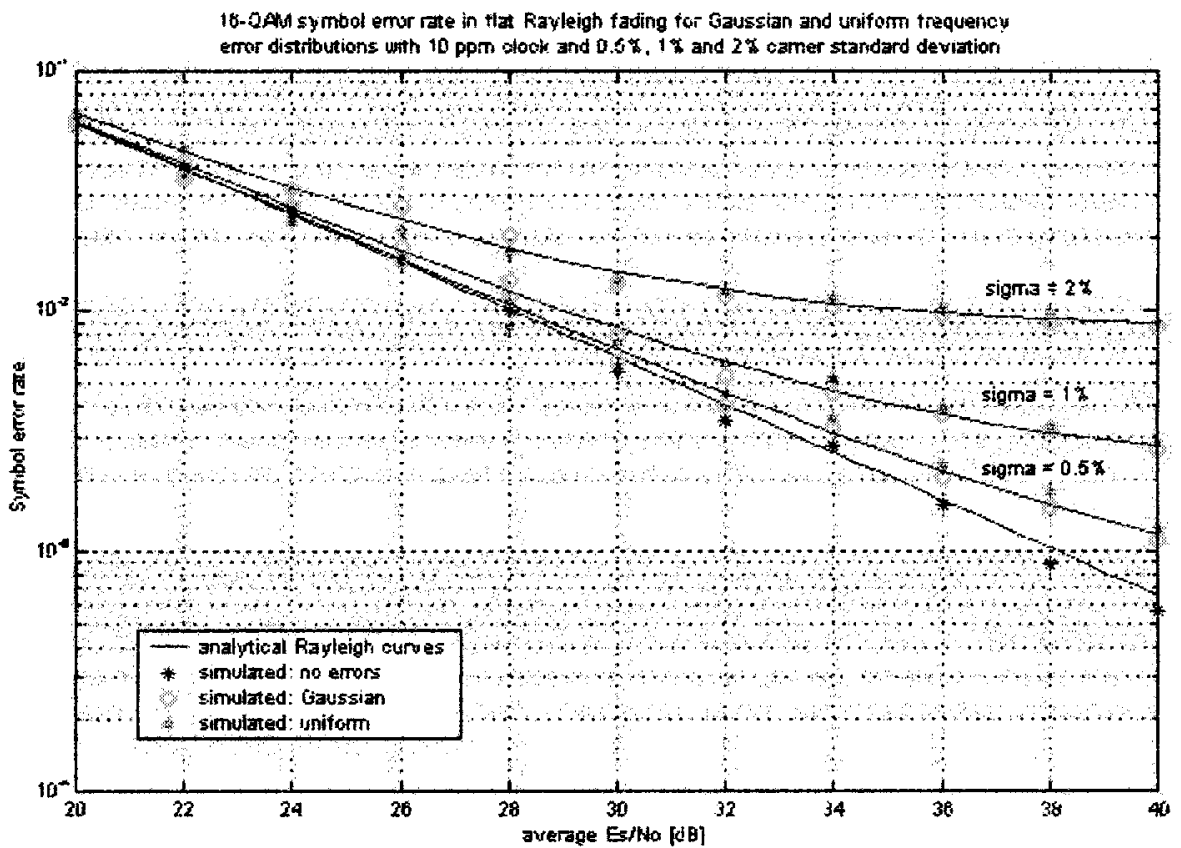

Fig. 14. Symbol error rate of 16-QAM over frequency selective fading channels.

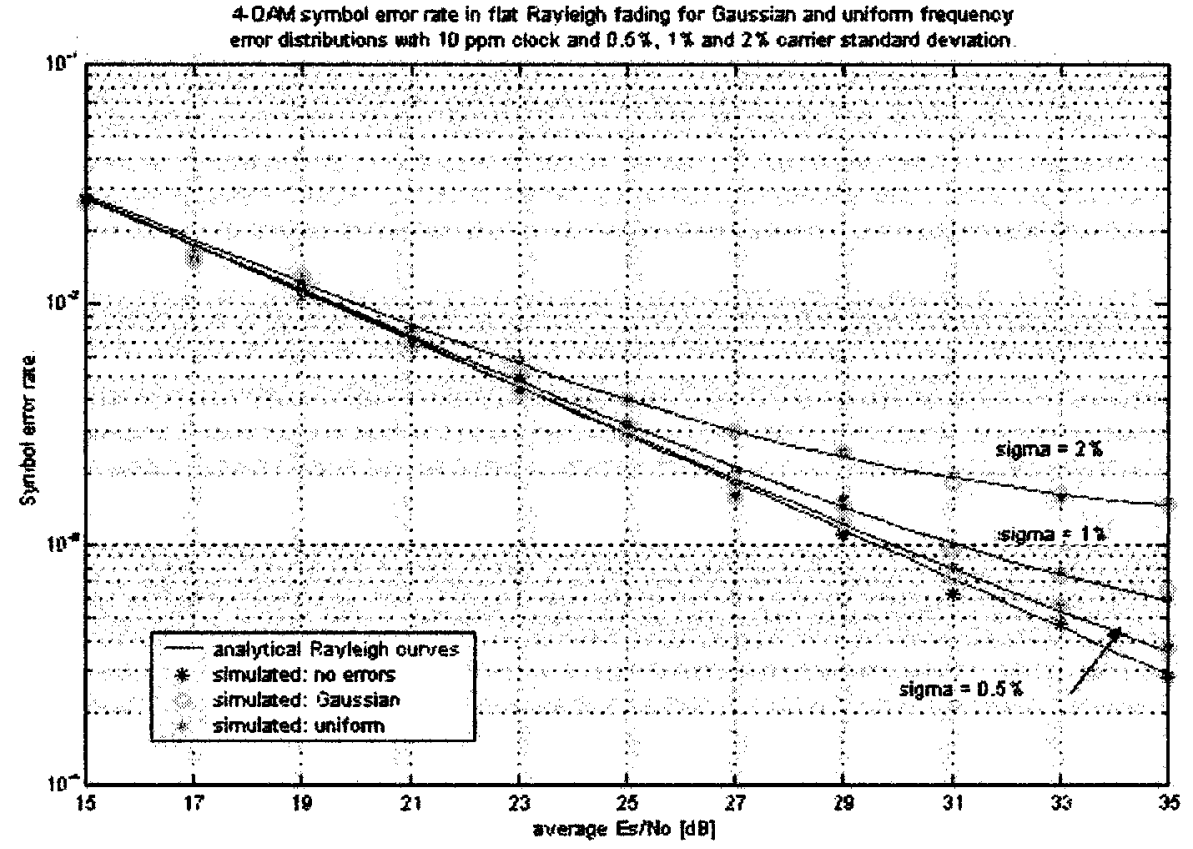

Fig. 15. Symbol error rate of 4-QAM over frequency selective fading channels.

16-QAM degradation due to frequency errors of $1 \%$, at an error rate of $10^{-2}$, is approximately $1 \mathrm{~dB}$.

- For both 4-QAM and 16-QAM and in the presence of clock and carrier frequency errors, the SER approaches an irreducible value as the signal-to-noise ratio increases.

This irreducible value can be predicted using (42) and (44) after substituting

$\left.\bar{\gamma}\right|_{\left(\mathrm{E}_{\mathrm{av}} / \mathrm{N}_{0}\right) \rightarrow \infty}=\frac{1}{\left[\left(\sigma_{\mathrm{cf}}^{2} \mathrm{~T}^{2}\right) \sum_{1 \neq \mathbf{n}}\left|\frac{1}{1-\mathrm{n}}\right|^{2}+\left(\frac{\sigma_{\mathrm{sc}}^{2}}{\mathrm{f}_{\mathrm{s}_{0}}^{2}}\right) \sum_{1 \neq \mathbf{n}}\left|\frac{1}{1-\mathrm{n}}\right|^{2}\right]}$.
Assuming carrier errors of $1 \%$, the irreducible error rates for 4-QAM and for 16-QAM are about $3 \times 10^{-4}$ and $2 \times 10^{-3}$ respectively. Assuming carrier errors of $2 \%$, the irreducible error rates for 4-QAM and for 16-QAM are increased to about $1 \times 10^{-3}$ and $8 \times 10^{-3}$, respectively.

\section{CONCLUSIONS}

In the following we summarize the conclusions to be drawn from our work. The main conclusion is that OFDM/16-QAM is usable for the uplink as long as the carrier errors remain within $1 \%$ of the tone spacing if the desired SER is about $10^{-2}$. 
OFDM/4-QAM is usable on the uplink if the carrier errors are maintained within $2 \times 10^{-2}$ of the subcarrier spacing.

Carrier Frequency Errors: It has been assumed that the uplink carriers are allocated to different users, which represents a worst case scenario. In this case, the carrier frequency errors associated with all subcarriers in an OFDM symbol begin to look like a random variable. By analyzing the uplink subject to carrier errors alone it became clear that:

- The carrier errors translate into additive interference at the output of the FFT demodulator.

- The average power of this interference varies as a function of the subcarrier index.

- The interference appears to follow a normal distribution even when the carrier errors are not normally distributed.

- The interference power and distribution appear to be independent of the QAM constellation used to modulate the individual subcarriers.

The simulation of a 256 carrier system assuming carrier errors with standard deviation of $1 \%$ (of the subcarrier spacing) suggests a signal-to-interference ratio of about $35 \mathrm{~dB}$. A $2 \%$ carrier errors causes an SIR of $29 \mathrm{~dB}$.

Sampling Clock Frequency Errors:

- The errors translate into additive interference at the output of the FFT demodulator.

- The average power of this interference shows very strong dependence on the subcarrier index.

- The interference appears to follow a normal distribution even when the sampling frequency errors are not normally distributed.

- The interference power and distribution appear independent of the QAM constellation used to modulate the individual subcarriers.

In a system with 256 carriers, and assuming a standard deviation of $10 \mathrm{ppm}$ for the sampling clock stability, we find a signal-to-interference ratio of about $70 \mathrm{~dB}$ for tone index 1 , and of $40 \mathrm{~dB}$ for tone index 256.

Symbol Timing Errors: Errors in the OFDM symbol timing translate into symbol rotations at the FFT output. This added rotation varies from one tone to the next, and is added to rotations caused by other factors, such as the channel responses. Therefore, symbol timing errors do not pose a threat since the overall rotation is compensated for by the frequency domain equalizer.

Average SER Performance: The uplink average SER performance has been examined both analytically and by simulation for the case of 4-QAM and 16-QAM. The main conclusions here are as follows:

- The SER performance was found somewhat tolerant to sampling clock stabilities of $10 \mathrm{ppm}$.

- The carrier frequency errors were found to be the major source of degradation because they lead to an irreducible error floor for both systems.

Assuming carrier errors of $1 \%$, the irreducible error floor for 4-QAM and 16-QAM is about $3 \times 10^{-4}$ and $2 \times 10^{-3}$ respectively. Assuming carrier errors of $2 \%$, the irreducible error floor for 4-QAM and 16-QAM is increased to about $1 \times 10^{-3}$ and $8 \times 10^{-3}$ respectively. In the case of 4-QAM we notice that frequency errors of $2 \%$ or less cause negligible degradation at error rates of $10^{-2}$ or more. The degradation increases to about $4 \mathrm{~dB}$ for error rates of $2 \times 10^{-3}$. In the case of $16-\mathrm{QAM}$ we find that frequency errors of $2 \%$ cause a $7 \mathrm{~dB}$ degradation at an error rate of $10^{-2}$. The 16-QAM degradation due to frequency errors of $1 \%$ and at error rate of $10^{-2}$ is approximately $1 \mathrm{~dB}$.

\section{APPENDIX \\ QAM SYMBOL ERROR RATE IN RAYLEIGH FADING CHANNELS}

The symbol error rate for an $M$-ary QAM transmission under AWGN conditions is given by

$$
\mathrm{P}_{\mathrm{e}}=1-\left(1-\mathrm{P}_{\sqrt{\mathrm{M}}}\right)^{2}=2 \cdot \mathrm{P}_{\sqrt{\mathrm{M}}}-\mathrm{P}_{\sqrt{\mathrm{M}}}^{2}
$$

with

$$
\mathrm{P}_{\sqrt{\mathrm{M}}}=\left(1-\frac{1}{\sqrt{\mathrm{M}}}\right) \cdot \operatorname{erfc}\left(\sqrt{\frac{3}{2(\mathrm{M}-1)} \cdot \frac{\mathrm{E}_{\mathrm{av}}}{\mathrm{N}_{0}}}\right)
$$

and with $E_{a v} / N_{0}$ being the average SNR per QAM symbol. At large SNR values the term $2 \cdot P_{\sqrt{M}}$ is dominant while $P_{\sqrt{M}}^{2}$ is a correction only. For Rayleigh fading channels the instantaneous SNR $\gamma$ has an exponential distribution with probability density function

$$
\mathrm{p}(\gamma)=\frac{1}{\bar{\gamma}} \cdot \exp \left(-\frac{\gamma}{\bar{\gamma}}\right) \quad \gamma \geq 0
$$

where $\bar{\gamma}$ is the average SNR and hence, the average symbol error probability is given by averaging the AWGN relation over the above distribution

$$
\overline{\mathrm{P}_{\mathrm{e}}}=\int_{0}^{\infty} \mathrm{P}_{\mathrm{e}}(\gamma) \cdot \mathrm{p}(\gamma) \mathrm{d} \gamma
$$

Changing the integration variable to $\mathrm{x}=\gamma / \bar{\gamma}$ we obtain

$$
\begin{aligned}
\overline{\mathrm{P}_{\mathrm{e}}} & =\int_{0}^{\infty} \mathrm{P}_{\mathrm{e}}(\mathrm{x}) \cdot \mathrm{e}^{-\mathrm{x}} \mathrm{dx} \\
& =2 \cdot \int_{0}^{\infty} \mathrm{P}_{\sqrt{\mathrm{M}}}(\mathrm{x}) \cdot \mathrm{e}^{-\mathrm{x}} \mathrm{dx}-\int_{0}^{\infty} \mathrm{P}_{\sqrt{\mathrm{M}}}^{2}(\mathrm{x}) \cdot \mathrm{e}^{-\mathrm{x}} \mathrm{dx}
\end{aligned}
$$

where

$$
\mathrm{P}_{\sqrt{\mathrm{M}}}(\mathrm{x})=\left(1-\frac{1}{\sqrt{\mathrm{M}}}\right) \cdot \operatorname{erfc}\left(\sqrt{\frac{3 \bar{\gamma}}{2(\mathrm{M}-1)} \cdot \mathrm{x}}\right) .
$$

We first evaluate the dominant term (first term) by expressing $\operatorname{erfc}(\mathrm{x})$ through $\operatorname{erf}(\mathrm{x})$ and then manipulating the resulting integral:

$$
\begin{aligned}
& \operatorname{erfc}(\mathrm{x})=1-\operatorname{erf}(\mathrm{x})=\frac{2}{\sqrt{\pi}} \cdot \int_{0}^{\mathrm{x}} \mathrm{e}^{-\mathrm{t}^{2}} \mathrm{dt} \\
& \int_{0}^{\infty} \mathrm{P}_{\sqrt{\mathrm{M}}}(\mathrm{x}) \cdot \mathrm{e}^{-\mathrm{x}} \mathrm{dx} \\
&=\left(1-\frac{1}{\sqrt{\mathrm{M}}}\right) \cdot\left[1-\int_{0}^{\infty} \operatorname{erf}(\sqrt{\mathrm{ax}}) \cdot \mathrm{e}^{-\mathrm{x}} \mathrm{dx}\right] \\
&=\left(1-\frac{1}{\sqrt{\mathrm{M}}}\right) \cdot[1-\mathrm{I}(\mathrm{a})]
\end{aligned}
$$

with

$$
\mathrm{a}=\frac{3 \bar{\gamma}}{2(\mathrm{M}-1)}
$$




$$
\begin{aligned}
I(a) & =\int_{0}^{\infty} \operatorname{erf}(\sqrt{\mathrm{ax}}) \cdot \mathrm{e}^{-\mathrm{x}} \mathrm{dx} \\
& =\frac{2}{\sqrt{\pi}} \int_{0}^{\infty} \mathrm{e}^{-\mathrm{x}}\left\{\int_{0}^{\sqrt{\mathrm{ax}}} \mathrm{e}^{-\mathrm{t}^{2}} \mathrm{dt}\right\} \mathrm{dx} \\
& =\frac{4}{\sqrt{\pi}} \int_{0}^{\infty}\left\{\int_{0}^{\sqrt{\mathrm{a}}} \mathrm{e}^{\left.-\left(1+\mathrm{u}^{2}\right) \mathrm{y}^{2} \mathrm{y}^{2} \mathrm{du}\right\}} \mathrm{dy}\right.
\end{aligned}
$$

after the change of variables $t=y u$ and $x=y^{2}$. Then,

$$
\begin{aligned}
I(a) & =\frac{4}{\sqrt{\pi}} \int_{0}^{\sqrt{a}} \mathrm{du}[\underbrace{-\left.\frac{\mathrm{e}^{-\left(1+\mathbf{u}^{2}\right) \mathrm{y}^{2} \mathrm{y}}}{2\left(1+\mathrm{u}^{2}\right)}\right|_{0} ^{\infty}}_{=0}+\frac{1}{2\left(1+\mathrm{u}^{2}\right)} \\
& \left.\cdot \int_{0}^{\infty} \mathrm{e}^{-\left(1+\mathbf{u}^{2}\right) \mathrm{y}^{2}} \mathrm{dy}\right] \\
= & 2 \int_{0}^{\sqrt{a}} \frac{\mathrm{du}}{\left(1+\mathrm{u}^{2}\right)^{3 / 2}} \cdot \frac{1}{\sqrt{\pi \frac{1}{1+u^{2}}}} \int_{0}^{\infty} \mathrm{e}^{-\left(\mathrm{y}^{2} / 1 /\left(1+\mathrm{u}^{2}\right)\right)} \mathrm{dy} \\
= & \int_{0}^{\sqrt{\mathrm{a}}} \frac{\mathrm{du}}{\left(1+\mathrm{u}^{2}\right)^{3 / 2}} \cdot
\end{aligned}
$$

In the last step we recognized a Gaussian distribution being integrated over $[0 \cdots \infty)$ which gives 0.5 . Performing now the $u=\tan (v)$ change of variables the remaining integral simplifies to:

$$
\mathrm{I}(\mathrm{a})=\int_{0}^{\operatorname{atan}(\sqrt{\mathrm{a}})} \cos (\mathrm{v}) \mathrm{dv}=\sin (\operatorname{atan}(\sqrt{\mathrm{a}}))=\sqrt{\frac{\mathrm{a}}{1+\mathrm{a}}} .
$$

Therefore, using the dominant term in relation (A.1) we can approximate the symbol error rate in Rayleigh fading as

$$
\overline{\mathrm{P}_{\mathrm{e}}} \cong 2 \cdot\left(1-\frac{1}{\sqrt{\mathrm{M}}}\right) \cdot\left[1-\sqrt{\frac{1}{1+\left(\frac{3 \bar{\gamma}}{2(\mathrm{M}-1)}\right)^{-1}}}\right]
$$

According to relation (A.4) the correction term is given by

$$
\begin{aligned}
\Delta \overline{\mathrm{P}_{\mathrm{e}}} & =-\int_{0}^{\infty} \mathrm{P}_{\sqrt{\mathrm{M}}}^{2}(\mathrm{x}) \cdot \mathrm{e}^{-\mathrm{x}} \mathrm{dx} \\
& =-\left(1-\frac{1}{\sqrt{\mathrm{M}}}\right)^{2} \cdot \int_{0}^{\infty}[\operatorname{erfc}(\sqrt{\mathrm{ax}})]^{2} \cdot \mathrm{e}^{-\mathrm{x}} \mathrm{dx} \\
& =-\left(1-\frac{1}{\sqrt{\mathrm{M}}}\right)^{2} \cdot \int_{0}^{\infty}[1-\operatorname{erf}(\sqrt{\mathrm{ax}})]^{2} \cdot \mathrm{e}^{-\mathrm{x}} \mathrm{dx} \\
& =-\left(1-\frac{1}{\sqrt{\mathrm{M}}}\right)^{2} \cdot[1-2 \mathrm{I}(\mathrm{a})+\mathrm{J}(\mathrm{a})]
\end{aligned}
$$

where we have defined

$$
\begin{aligned}
\mathrm{J}(\mathrm{a}) & =\int_{0}^{\infty}[\operatorname{erf}(\sqrt{\mathrm{ax}})]^{2} \cdot \mathrm{e}^{-\mathrm{x}} \mathrm{dx} \\
& =\frac{4}{\pi} \int_{0}^{\infty} \mathrm{e}^{-\mathrm{x}}\left\{\int_{0}^{\sqrt{\mathrm{ax}}} \mathrm{e}^{-\mathrm{t}_{1}^{2}} \mathrm{dt}_{1} \int_{0}^{\sqrt{\mathrm{ax}}} \mathrm{e}^{-\mathrm{t}_{2}^{2}} \mathrm{dt_{2 }}\right\} \mathrm{dx} .
\end{aligned}
$$

Using the change of variables $t_{1}=\sqrt{\mathrm{x}}-\mathrm{y}_{1}$ and $\mathrm{t}_{2}=\sqrt{\mathrm{x}} \cdot \mathrm{y}_{2}$ the equation transforms into

$$
\begin{aligned}
\mathrm{J}(\mathrm{a}) & =\frac{4}{\pi} \int_{0}^{\infty} \mathrm{xe}^{-\mathrm{x}}\left\{\int_{0}^{\sqrt{\mathrm{a}}} \mathrm{e}^{-\mathrm{xy}_{1}^{2}} \mathrm{dy}_{1} \int_{0}^{\sqrt{\mathrm{a}}} \mathrm{e}^{-\mathrm{xy}_{2}^{2}} \mathrm{dy}_{2}\right\} \mathrm{dx} \\
& =\frac{4}{\pi} \int_{0}^{\sqrt{\mathrm{a}}} \int_{0}^{\sqrt{\mathrm{a}}}\left\{\int_{0}^{\infty} \mathrm{xe}^{-\left(1+\mathrm{y}_{1}^{2}+\mathrm{y}_{2}^{2}\right) \mathrm{x}_{1}} \mathrm{dx}^{\mathrm{a}}\right\} \mathrm{dy}_{1} \mathrm{dy}_{2} \\
& =\frac{4}{\pi} \int_{0}^{\sqrt{\mathrm{a}}} \int_{0}^{\sqrt{\mathrm{a}}} \frac{1}{\left(1+\mathrm{y}_{1}^{2}+\mathrm{y}_{2}^{2}\right)^{2}} \mathrm{dy}_{1} \mathrm{dy}_{2} .
\end{aligned}
$$

We now switch to polar coordinates and we notice that the integrand takes on the same values under the $\mathrm{y}_{1} \leftrightarrow \mathrm{y}_{2}$ exchange of coordinates. Therefore, it is sufficient to integrate over only one of the shaded regions represented in the adjacent figure.

$$
\begin{aligned}
\mathrm{J}(\mathrm{a}) & =\frac{8}{\pi} \int_{0}^{\pi / 4}\left\{\int_{0}^{\sqrt{\mathrm{a}} / \cos (\theta)} \frac{\mathrm{r}}{\left(1+\mathrm{r}^{2}\right)^{2}} \mathrm{dr}\right\} \mathrm{d} \theta \\
& =\frac{4}{\pi} \int_{0}^{\pi / 4}\left\{\left.\frac{-1}{1+\mathrm{r}^{2}}\right|_{0} ^{\sqrt{\mathrm{a}} / \cos (\theta)}\right\} \mathrm{d} \theta \\
& =1-\frac{4}{\pi} \int_{0}^{\pi / 4} \frac{1}{1+\frac{1}{[\cos (\theta)]^{2}}} \mathrm{~d} \theta .
\end{aligned}
$$

With a new change of variable where $\mathrm{v}=\tan (\theta)$ we obtain

$$
\begin{aligned}
\mathrm{J}(\mathrm{a}) & =1-\frac{4}{\pi} \int_{0}^{1} \frac{1}{\left(1+\mathrm{v}^{2}\right)\left[1+\mathrm{a}\left(1+\mathrm{v}^{2}\right)\right]} \mathrm{dv} \\
& =\frac{4}{\pi} \cdot \sqrt{\frac{\mathrm{a}}{1+\mathrm{a}}} \cdot \operatorname{atan}\left(\sqrt{\frac{\mathrm{a}}{1+\mathrm{a}}}\right)
\end{aligned}
$$

and the correction term is

$$
\Delta \overline{\mathrm{P}_{\mathrm{e}}}=-\left(1-\frac{1}{\sqrt{\mathrm{M}}}\right)^{2} \cdot\left[1-2 \cdot \xi+\frac{4}{\pi} \cdot \xi \cdot \operatorname{atan}(\xi)\right]
$$

with

$$
\xi=\sqrt{\frac{\mathrm{a}}{1+\mathrm{a}}} .
$$


In conclusion, the exact relation giving the average symbol error rate is found to be

$$
\begin{aligned}
\overline{\mathrm{P}_{\mathrm{e}}}= & 2 \cdot\left(1-\frac{1}{\sqrt{\mathrm{M}}}\right) \cdot(1-\xi)-\left(1-\frac{1}{\sqrt{\mathrm{M}}}\right)^{2} \\
& \cdot\left[1-2 \cdot \xi+\frac{4}{\pi} \cdot \xi \cdot \operatorname{atan}(\xi)\right]
\end{aligned}
$$

where $\xi$ and $a$ are given in (A.16) and (A.6), respectively.

\section{REFERENCES}

[1] M. Alard and R. Lassalle, "Principles of modulation and channel coding for digital broadcasting for mobile receivers," EBU Technical Review, pp. 168-190, Aug. 1987.

[2] J. Chuang, L.J. Cimini, G. Ye Li, B. McNair, N. Sollenberger, H. Zhao, L. Lin, and M. Suzuki, "High-speed wireless data access based on combining EDGE with wideband OFDM," IEEE Communications Magazine, pp. 92-98, Nov. 1999.

[3] R. van Nee, G. Awater, M. Morikura, H. Takanashi, M. Webster, and K.W. Halford, "New high-rate wireless LAN standards," IEEE Communications Magazine, pp. 82-88, Dec. 1999.

[4] A. Nordbotten, "LMDS systems and their application," IEEE Communications Magazine, pp. 150-154, June 2000.

[5] S. Verdú, "Wireless bandwidth in the making," IEEE Communications Magazine, pp. 53-58, July 2000.

[6] J. Chuang and N. Sollenberger, "Beyond 3G: wideband wireless data access based on OFDM and dynamic packet assignment," IEEE Communications Magazine, pp. 78-87, July 2000.

[7] M. Moeneclaey, "The effect of synchronization errors on the performance of orthogonal frequency division multiplexed (OFDM) systems," in Proc. COST 254, July 1997.

[8] T. Pollet, M. van Bladel, and M. Moeneclaey, "BER sensitivity of OFDM systems to carrier frequency offset and Wiener phase noise," IEEE Trans. Commun., pp. 191-193, Feb. 1995.

[9] R.D. Roberts, "Qualitative analysis of the impact of clock timing error and/or frequency offsets on an OFDM waveform demodulator," in SouthCom 1996, pp. 80-85.

[10] T. Pollet and M. Moeneclaey, "The effect of carrier frequency offset on the performance of band limited single carrier and OFDM signals," in Globecom 1996, pp. 719-723.
Mohammed S. El-Tanany obtained the B.Sc. and M.Sc. in electrical engineering in 1974 and 1978 respectively, both from Cairo University in Giza, Egypt, and the Ph.D. in electrical engineering from Carleton University, Ottawa, ON, Canada in 1983. He worked with the Advanced Systems division of Miller Communications in Kanata, Ontario from 1982 to 1985 with principal involvement in the research and development of digital transmission equipment for mobile satellite type of applications and also for VHF airborne high-speed down links. He joined Carleton University in 1985, initially as a research associate in the area of wireless communications for mobile and indoor communications. He is currently a professor with the Department of Systems and Computer Engineering where he is actively involved in several research programs that deal with digital transmission in the PCS and millimeter wave frequency bands, with emphasis on channel measurements, modeling as well as modulation/coding for frequency selective fading channels.

Yiyan Wu is a senior research scientist with the Communications Research Centre, Ottawa, Canada. His research interests include digital video compression and transmission, high definition television (HDTV), signal and image processing, satellite and mobile communications. He is actively involved in the ATSC technical and standard activities and ITU-R digital television and data broadcasting studies. He is an IEEE Fellow, an adjunct professor of Carleton University, Ottawa, Canada, a Member of the IEEE Broadcast Technology Society Administrative Committee and a member of the ATSC Executive Committee (representing IEEE).

László Házy obtained a B.Sc. in electronics and telecommunications from the Polytechnic Institute of Bucharest, Romania in 1992 and a M.Eng. in electrical engineering from Carleton University, Canada, in 1997. Currently he is a Ph.D. candidate at Carleton University. Between 1992 and 1995 he was an assistant professor with the Department of Electronics and Computers at Transilvania University, Romania, working in the area of radio and microwave communications. Between 1993 and 1995 he was also involved with the Research Institute for Computer Technology, Brasov, Romania. His research interests include digital communications theory and various aspects of wireless communication systems, and he is currently working on OFDM and multicarrier spread spectrum systems. 